\author{
SANDIA REPORT \\ SAND2010-7802 \\ Unlimited Release \\ Printed November 2010
}

\title{
Durability Study of a Vehicle-scale Hydrogen Storage System
}

\author{
Terry A. Johnson \\ Daniel E. Dedrick \\ Richard Behrens
}

Prepared by

Sandia National Laboratories

Albuquerque, New Mexico 87185 and Livermore, California 94550

Sandia National Laboratories is a multi-program laboratory managed and operated by Sandia Corporation, a wholly owned subsidiary of Lockheed Martin Corporation, for the U.S. Department of Energy's National Nuclear Security Administration under contract DE-AC04-94AL85000.

Approved for public release; further dissemination unlimited. 
Issued by Sandia National Laboratories, operated for the United States Department of Energy by Sandia Corporation.

NOTICE: This report was prepared as an account of work sponsored by an agency of the United States Government. Neither the United States Government, nor any agency thereof, nor any of their employees, nor any of their contractors, subcontractors, or their employees, make any warranty, express or implied, or assume any legal liability or responsibility for the accuracy, completeness, or usefulness of any information, apparatus, product, or process disclosed, or represent that its use would not infringe privately owned rights. Reference herein to any specific commercial product, process, or service by trade name, trademark, manufacturer, or otherwise, does not necessarily constitute or imply its endorsement, recommendation, or favoring by the United States Government, any agency thereof, or any of their contractors or subcontractors. The views and opinions expressed herein do not necessarily state or reflect those of the United States Government, any agency thereof, or any of their contractors.

Printed in the United States of America. This report has been reproduced directly from the best available copy.

Available to DOE and DOE contractors from

U.S. Department of Energy

Office of Scientific and Technical Information

P.O. Box 62

Oak Ridge, TN 37831

Telephone: $\quad$ (865) 576-8401

Facsimile: $\quad$ (865) 576-5728

E-Mail: $\quad$ reports@adonis.osti.gov

Online ordering: http://www.osti.gov/bridge

Available to the public from

U.S. Department of Commerce

National Technical Information Service

5285 Port Royal Rd.

Springfield, VA 22161

Telephone: $\quad$ (800) 553-6847

Facsimile: $\quad$ (703) 605-6900

E-Mail: $\quad$ orders@ntis.fedworld.gov

Online order: $\quad$ http://www.ntis.gov/help/ordermethods.asp?loc=7-4-0\#online




SAND2010-7802

Unlimited Release

Printed November 2010

\title{
Durability Study of a Vehicle-scale Hydrogen Storage System
}

\author{
Terry Johnson ${ }^{\mathrm{a}}$, Daniel Dedrick ${ }^{\mathrm{a}}$, and Richard Behrens ${ }^{\mathrm{b}}$ \\ ${ }^{\mathrm{a}}$ Thermal/Fluids Science and Engineering 8365 \\ ${ }^{\mathrm{b}}$ Remote Sensing and Energetic Materials 8128 \\ Sandia National Laboratories \\ P.O. Box 969 \\ Livermore, CA 94551
}

\begin{abstract}
Sandia National Laboratories has developed a vehicle-scale demonstration hydrogen storage system as part of a Work for Others project funded by General Motors. This Demonstration System was developed based on the properties and characteristics of sodium alanates which are complex metal hydrides. The technology resulting from this program was developed to enable heat and mass management during refueling and hydrogen delivery to an automotive system. During this program the Demonstration System was subjected to repeated hydriding and dehydriding cycles to enable comparison of the vehicle-scale system performance to small-scale sample data. This paper describes the experimental results of life-cycle studies of the Demonstration System.
\end{abstract}

Two of the four hydrogen storage modules of the Demonstration System were used for this study. A well-controlled and repeatable sorption cycle was defined for the repeated cycling, which began after the system had already been cycled forty-one times. After the first nine repeated cycles, a significant hydrogen storage capacity loss was observed. It was suspected that the sodium alanates had been affected either morphologically or by contamination. The mechanisms leading to this initial degradation were investigated and results indicated that water and/or air contamination of the hydrogen supply may have lead to oxidation of the hydride and possibly kinetic deactivation.

Subsequent cycles showed continued capacity loss indicating that the mechanism of degradation was gradual and transport or kinetically limited. A materials analysis was then conducted using established methods [6] including treatment with carbon dioxide to react with sodium oxides that 
may have formed. The module tubes were sectioned to examine chemical composition and morphology as a function of axial position. The results will be discussed. 


\section{ACKNOWLEDGMENTS}

Funding for this effort was provided by the US Department of Energy Fuel Cell Technologies Program. The GM demonstrations system was funded by GM under the program management of James Spearot. The authors are indebted to the mechanical design, electrical design and experimental expertise of Yon Perras, George Sartor and Mark Zimmerman. 


\section{CONTENTS}

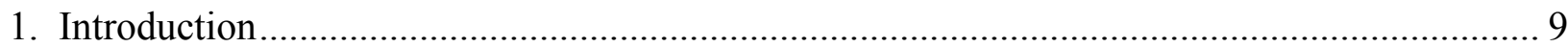

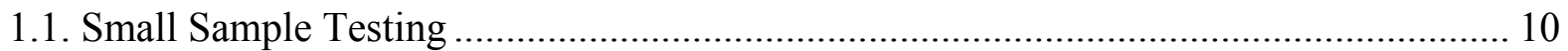

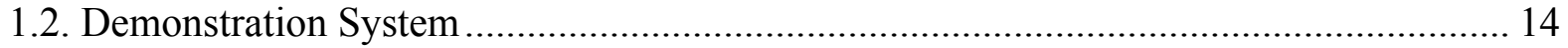

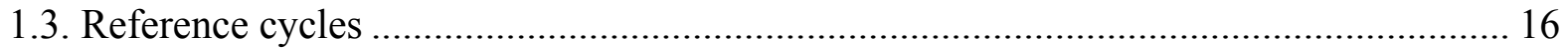

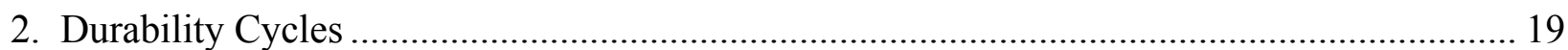

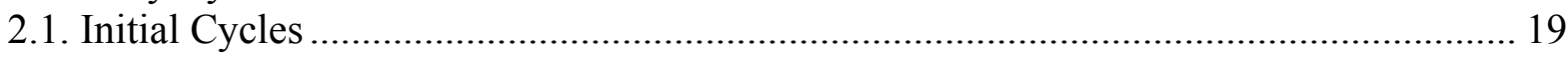

2.1.1. Absorption Cycle Procedure ………………………………………………. 19

2.1.2. Desorption Cycle Procedure ......................................................................... 20

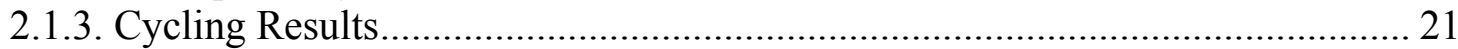

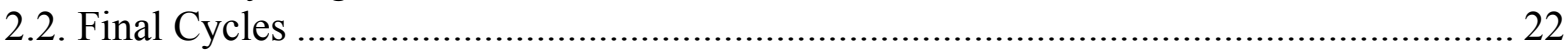

2.2.1. Absorption Cycle Procedure ……………………........................................... 22

2.2.2. Desorption Cycle Procedure............................................................................... 23

2.2.3. Cycle Results ........................................................................................... 24

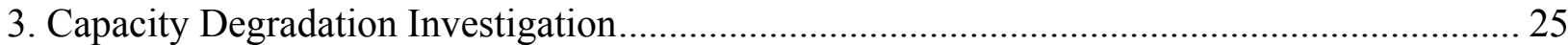

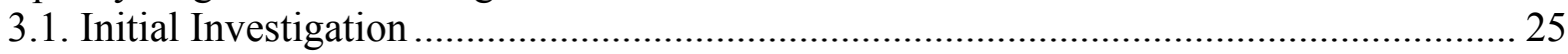

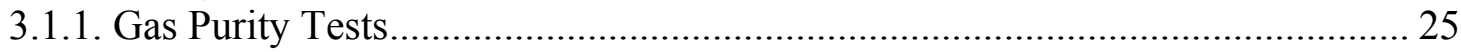

3.1.2. Capacity and Sorption Rate Tests .............................................................. 26





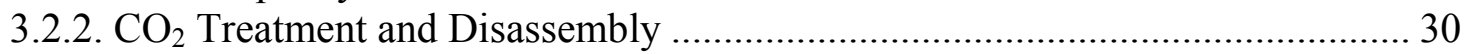

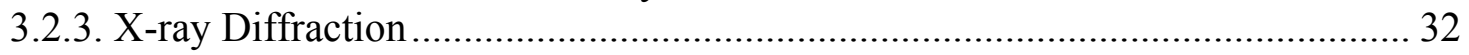

3.2.4. Thermo-gravimetric Analysis with Mass Spectrometry ................................... 33

4. Summary and Conclusions …………………….............................................................. 39

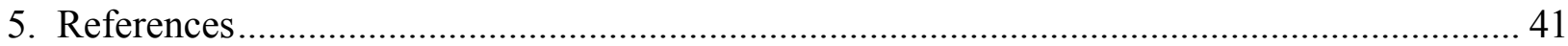

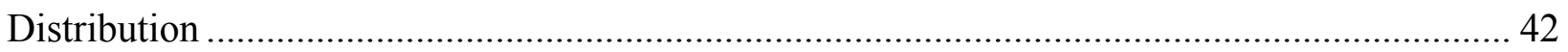

\section{FIGURES}

Figure 1. Sample holder for 100 cycle durability test of sodium alanate .................................... 10

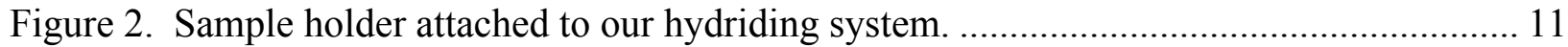

Figure 3. Absorption data from the 100 cycle tests. ................................................................... 11

Figure 4. Small sample capacity degradation as a function of cycle number for ten minute and

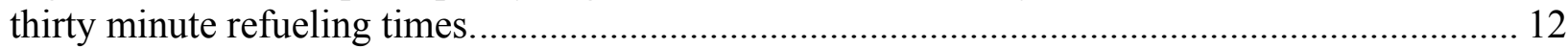

Figure 5. Relative kinetic and capacity comparison for fresh, aged, and re-milled samples



Figure 6. Demonstration System hydrogen storage module..................................................... 15

Figure 7. Solid model of module tube with end detail shown. ....................................................... 15

Figure 8. Reference absorption cycles run with the Demonstration System ................................ 16

Figure 9. Demonstration System capacity degradation as a function of cycle number ................ 17 Figure 10. Example of the initial absorption and desorpton conditions used for the durability study 
Figure 11. Rapid capacity drop during initial durability study cycles .................................. 22

Figure 12. Example of the new desorption cycle for the durability study .............................. 23

Figure 13. Capacity loss over cycles 58-80 .................................................................... 24

Figure 14. Module capacity and kinetics comparison following initial durability cycles .......... 28

Figure 15. Infrared image of Module 3 while exposed to $25 \mathrm{psi} \mathrm{CO}_{2}$. The exotherm suggests

carbonate formation from oxidized alanates................................................................ 30

Figure 16. Removal of the Module \#3 heat exchanger shell to separate individual tubes

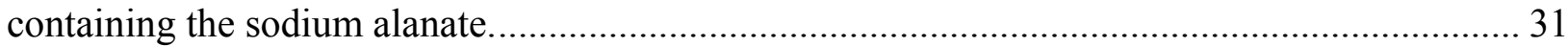

Figure 17. Infrared image of a module tube during a final $\mathrm{CO}_{2}$ treatment............................ 31

Figure 18. A sectioned tube from Module 3 with the sodium alanate removed........................ 32

Figure 19. XRD powder diffractometry indicated that only the sample near the inlet had

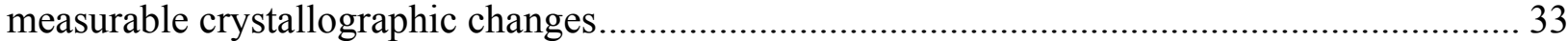

Figure 20. Comparison of the rate of evolution of $\mathrm{H}_{2}$ taken from four regions in the reactor.

Results indicate that residual uncatalyzed $\mathrm{Na}_{3} \mathrm{AlH}_{6}$ exists in the inaccessible areas of the bed. . 34

Figure 21. Comparison of the rate of evolution of $\mathrm{H}_{2}$ from the decomposition of Ti-catalyzed

$\mathrm{NaAlH} 4$ (dotdotdash) with the catalyzed samples taken from the inlet and far end of the reactor.

Results indicate the presence of uncatalyzed $\mathrm{Na}_{3} \mathrm{AlH}_{6}$ in the far end and possibly the presence of

catalyzed $\mathrm{Na}_{3} \mathrm{AlH}_{6}$ in the inlet sample. 35

Figure 22. The sample near the inlet indicates significant amounts of $\mathrm{CO}_{\mathrm{x}}$ evolving during

heating. This is a result of the $\mathrm{CO}_{2}$ treatment process, which produces sodium bicarbonate ...... 36

\section{TABLES}

Table 1. Gas species found in hydrogen supply (ppm) ...................................................... 26

Table 2. Comparison of module capacities before and after capacity loss ............................. 27

Table 3. Comparison of module capacities following extended absorption ............................. 28

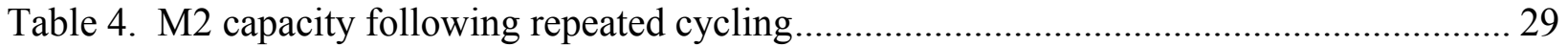




\section{NOMENCLATURE}

Sodium alanates

Hex phase

Tet phase
$\mathrm{NaAlH}_{4}, \mathrm{Na}_{3} \mathrm{AlH}_{6}$, and its decomposition products The $\mathrm{Na}_{3} \mathrm{AlH}_{6}$ phase, in which approximately $67 \%$ of the deliverable hydrogen has been released.

The $\mathrm{NaAlH}_{4}$ phase, in which no hydrogen has been released. 


\section{INTRODUCTION}

Advanced hydrogen storage is a key enabling technology for the commercialization of passenger vehicles powered by fuel cells. The majority of fuel cell vehicles on the road today utilize either compressed gas or liquid hydrogen storage systems. These physical containment storage tanks will be sufficient for the initial launch of hydrogen fueled vehicles, but do not satisfy the USDOE and auto industry requirements for more compact, lighter, and less expensive methods. Higher efficiency hydrogen storage systems will enable a broader market penetration of clean fuel cell technologies for on-road, off-road, and stationary applications.

General Motors has developed a broad portfolio of hydrogen storage technologies as part of their fuel cell vehicle program, including complex metal hydrides. Complex metal hydrides developed for automotive applications offer the benefit of high hydrogen capacity by weight and volume. Challenges do exist; characteristics such as relatively high reaction enthalpies, low thermal conductivity, elevated hydrogen release temperatures, and slow kinetics at lower temperatures require technology development.

In addition to the development of new materials under other programs, GM partnered with Sandia National Laboratories to develop an advanced hydrogen storage system based on prototypical complex metal hydrides, sodium alanates. When catalyzed, sodium alanates release and absorb hydrogen in a two step decomposition and recombination reaction shown below:

$$
\begin{aligned}
& \mathrm{NaAlH}_{4} \Leftrightarrow 1 / 3 \mathrm{Na}_{3} \mathrm{AlH}_{6}+2 / 3 \mathrm{Al}+\mathrm{H}_{2} \\
& \quad \begin{array}{l}
\text { and, } \\
1 / 3 \mathrm{Na}_{3} \mathrm{AlH}_{6}+2 / 3 \mathrm{Al}+\mathrm{H}_{2} \Leftrightarrow \mathrm{NaH}+\mathrm{Al}+3 / 2 \mathrm{H}_{2}
\end{array}
\end{aligned}
$$

This material was chosen as the storage medium for the GM/Sandia hydrogen storage engineering project due to its relative advanced state of development and characteristic physical properties. This project was a five year effort to develop an optimized system design utilizing advanced concepts for hydrogen storage with complex hydrides. The culmination of this project is a $3 \mathrm{~kg}$ stored hydrogen demonstration system that was designed, fabricated, and tested at Sandia $[1,2]$.

As part of the development of the optimal sodium alanate formulation, we evaluated the performance and cycling stability of the material in small scale tests including cycle durability tests. The cycle durability tests investigated the capacity and kinetic degradation as a function of hydrogen sorption cycle. Once the Demonstration System was completed, a specific absorption cycle was used to track the material performance while we performed various tests for GM. These reference cycle results were compared with the small sample results for consistency. The current work began as an extension of the GM reference cycles to track performance out to 100 cycles with the vehicle scale system.

A new tracking cycle was developed and implemented, but after the first cycles were completed a degradation in hydrogen capacity was observed that was much greater than expected. An investigation to understand this degradation will be described. Following a complete purge of 
the hydrogen supply system, subsequent hydrogen absorption and desorption cycles also showed a greater than expected drop in the material capacity. These results will be described along with a series of qualitative and quantitative experiments to understand the cause including X-ray diffraction and thermogravimetric analysis.

\subsection{Small Sample Testing}

The cycle durability study with the small sample was performed while sodium alanate was being produced for the Demonstration System. The material for the small scale tests was taken from a batch of Demonstration System material. The sample included the excess aluminum and the $\mathrm{TiCl}_{3}$ catalyst, but was taken prior to the addition of thermal conductivity enhancer [3-5]. About 19 grams of this modified sodium alanate was taken from one of the 500 gram batches prepared using Fritsch P5 planetary mills.

A sample holder was designed specifically for this testing and is shown in Figure 1. The vessel was designed to hold about 20 grams of material and included three thermocouple wells; one embedded in the sample and two monitoring the wall temperature.

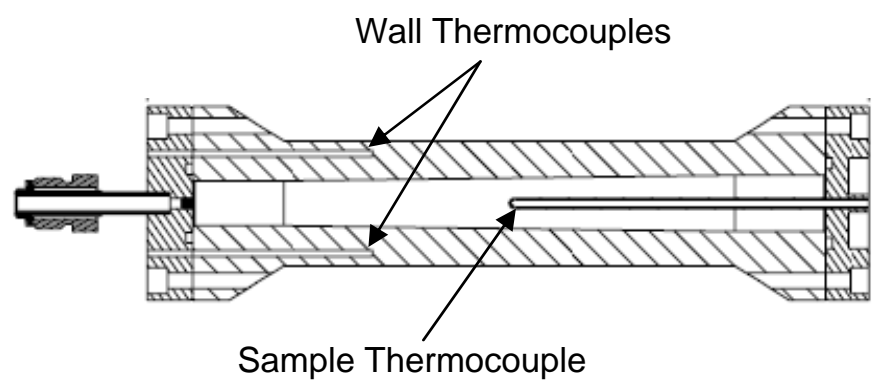

Figure 1. Sample holder for 100 cycle durability test of sodium alanate

A repeatable hydrogen sorption procedure was specified for the 100 cycle tests; the sample was preheated to $140{ }^{\circ} \mathrm{C}$ and then exposed to hydrogen at a pressure regulated at $1800 \mathrm{psi}$ for a period of 30 minutes. To improve the kinetics of absorption of the second or tetrahydride phase, the temperature was ramped to $155^{\circ} \mathrm{C}$ at the start of the absorption.

Following absorption, the pressure in the sample was lowered and the sample temperature was increased from $155^{\circ} \mathrm{C}$ to $200{ }^{\circ} \mathrm{C}$ and then held for 1 hour. The heater power and thermal capacity of the system was balanced such that, during the temperature ramp, the tetrahydride phase would fully decompose by the time the temperature reached about $175^{\circ} \mathrm{C}$. The rate would then fall to zero until the temperature was high enough for the hexahydride phase to decompose at around $190{ }^{\circ} \mathrm{C}$. The 1-hour duration was long enough for the desorption rate to fall to near zero.

Figure 2 shows a loaded sample holder attached to our hydriding system. Thermocouples can be seen protruding from the wells in the top of the vessel which is surrounded by a thick heater. The hydriding station is a Sieverts-type apparatus which allows for semi-automated cycling of 
hydrogen storage materials. By recording temperatures and pressures of calibrated volumes, both absorption and desorption rates and capacities are calculated.

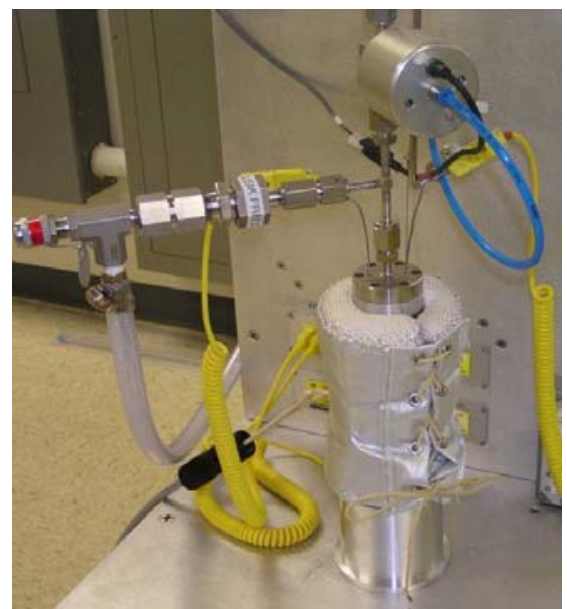

Figure 2. Sample holder attached to our hydriding system.

Figure 3 shows hydrogen capacity data from specified absorption cycles spanning the range from cycle 5 to cycle 96 . A reduction in the hydriding kinetics can be seen by the change in slope of the curves. Both the hexahydride $(0$ to $\sim 1.3 \mathrm{wt} \%)$ and the tetrahydride $(>\sim 1.3 \mathrm{wt} \%)$ phases are formed at slower rates as cycle number increases. In addition, the capacity after the full $30 \mathrm{~min}$ absorption period decreases with cycle.

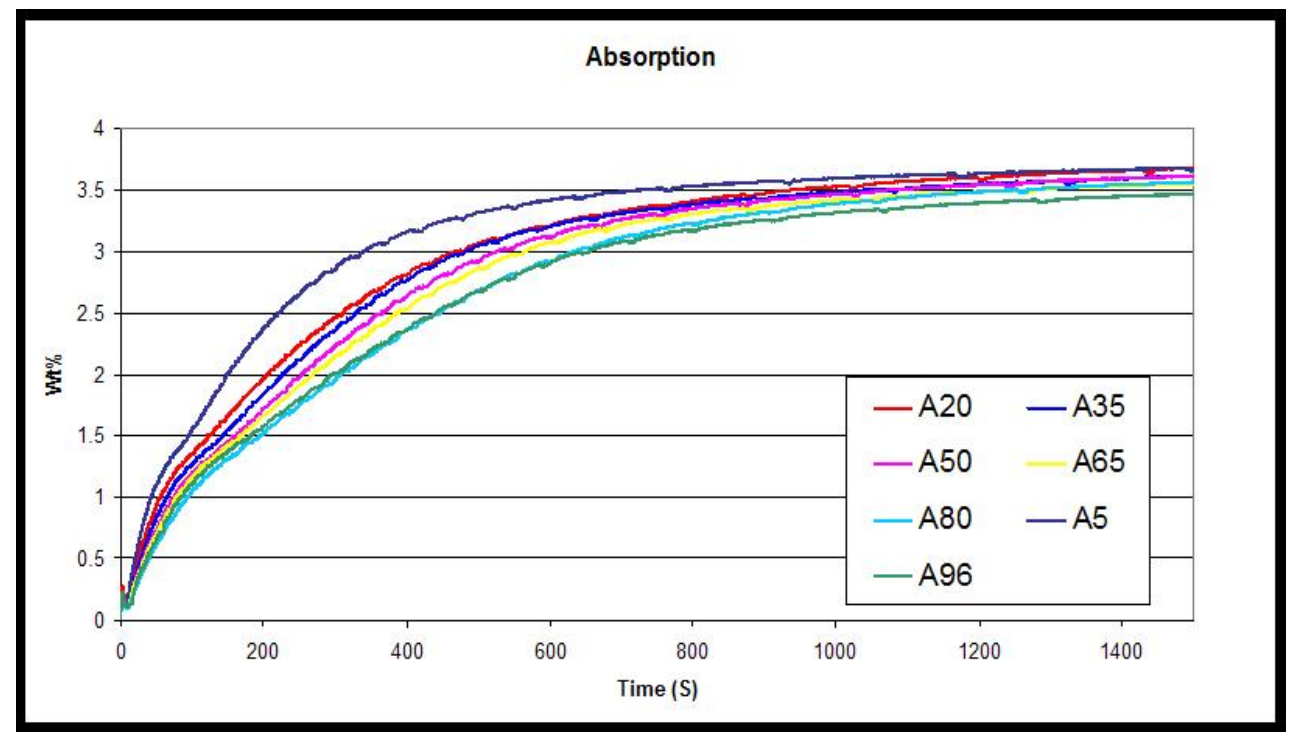

Figure 3. Absorption data from the 100 cycle tests.

This capacity reduction is shown as a function of cycle in Figure 4. Note that for finite absorption times, hydrogen capacity should be considered an 'effective capacity' since the value cannot be separated from sorption rate unless the material is given an infinite amount of time to fully hydride. Nevertheless, we are more interested in effective capacity for vehicle applications 
since consumers are unlikely to accept long refueling times while alternatives exist. Figure 4 shows effective capacity at ten and thirty minutes over 96 absorption cycles. The figure also shows a best linear fit to each set of data. Note that the ten minute capacity decreases at a greater rate than the thirty minute capacity indicating a greater effect of kinetics. The ten minute capacity loss is approximately $0.006 \mathrm{wt} \%$ per cycle, while the thirty minute capacity loss is approximately $0.003 \mathrm{wt} \%$ per cycle. It should be noted that this sample did not contain the expanded natural graphite (ENG) that was used to improve the thermal conductivity of the hydride. Subsequent testing of samples with the ENG fiber in the sample holder indicated a similar trend in degradation, however with a larger total loss in capacity. Total loss in capacity during 30 minute absorptions was found to be $0.01 \mathrm{wt} \%$ per cycle. The increased loss in capacity due to the ENG fibers is discussed in the sections below.

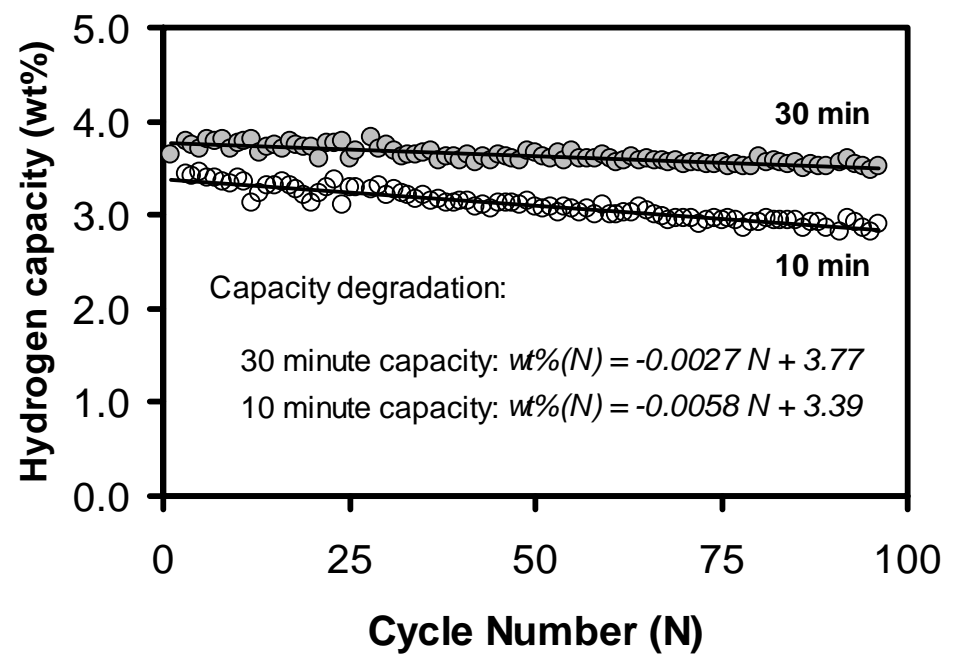

Figure 4. Small sample capacity degradation as a function of cycle number for ten minute and thirty minute refueling times.

As part of the GM-funded program, this capacity degradation was investigated with a number of microscopy and analytical techniques. Several causes for this degradation are possible. These include:

1) Sample contamination with organic material entrained in the hydrogen stream

2) Oxidation of the alanate from $\mathrm{O}_{2}$ and/or $\mathrm{H}_{2} \mathrm{O}$ entrained in the hydrogen stream

3) Morphological changes in the material that reduces the reactive surface area of the solid reacting species

4) A decrease in catalytic activity due to changes in the titanium catalyst

To better understand potential causes of the degradation in performance, the total hydrogen capacities of each phase of the material were measured. To accomplish this, the completely dehydrogenated 100-cycle material was hydrogenated under temperature and pressure conditions that thermodynamically limit the absorption to the hexahydride phase $\left(\mathrm{Na}_{3} \mathrm{AlH}_{6}\right)$. That material was then further hydrogenated fully to the tetrahydride phase $\left(\mathrm{NaAlH}_{4}\right)$ until equilibrium was attained. Similar absorption tests were conducted on material that had been subjected to only 10 
absorption/desorption cycles. These tests indicated that both alanate phases of the aged material showed nearly a $10 \%$ reduction in full capacity relative to that observed for the fresh material. Hence, the performance degradation over 100-cycles was not phase dependent.

A series of tests were conducted to detect material contamination. The hydrogen used for cycling the alanate was tested for purity. The hydrogen had undetectable levels of hydrocarbons, 5.6 ppm of $\mathrm{H}_{2} \mathrm{O}$, and 1.3 ppm levels of $\mathrm{O}_{2}$. In theory, these water and oxygen levels should be insufficient to result in significant oxidation of the aged sodium alanate depending on assumptions for exposure time and assuming contamination is stoichiometric.

To investigate the presence of hydrocarbon or oxidation contamination in the aged sample, thermogravimetric decomposition, Al-NMR spectra, and Fourier Transform Infrared Spectra (FTIR) were taken of the fresh and cycled materials. Thermogravimetric measurements were performed on both the fresh and cycled samples at temperatures up to $1000{ }^{\circ} \mathrm{C}$. The massspectrum of the gas evolving from the sample did not indicate the presence of any hydrocarbon contamination, however, the possible presence of low-level sodium oxidation was identified. AL-NMR spectra for the fresh and aged materials were obtained to investigate the presence of aluminum oxidation. These spectra did not indicate the presence of aluminum oxides. FTIR measurements were made on the fresh and aged materials to investigate the presence of hydrocarbon contamination in the samples. Hydrocarbon $\mathrm{C}-\mathrm{H}$ stretches would be expected to be observed between 3000 and $2840 \mathrm{~cm}^{-1}$ if the material were contaminated with organic material. The spectra did not indicate the presence of organic material contamination.

X-ray diffraction (XRD) spectra were taken of the two samples. The XRD spectra did show subtle changes in the aged material relative to the fresh material. In particular, there are changes in the shape of the spectra at $38.5^{\circ}$ two-theta angle. Aluminum and sodium oxides were not apparent in the XRD spectra.

To further investigate morphological changes, SEM/EDX measurements were made on the fresh and aged materials. SEM imaging indicated changes in the particle appearance (morphology) with cycling. Two distinct types of particles are observed in the SEM images: a "spherical" phase and a "fine cluster" phase. The spherical phase is more prevalent in the fresh materials while the fine cluster is more likely to appear in the aged materials. Analysis using EDX capabilities of $3 \mu \mathrm{m}$ and smaller particles indicated that the bulk properties of the spherical phase tended to be predominately aluminum with very little detectable titanium, while the fine clusters tended to be titanium rich sodium particles.

To determine whether these morphological effects had in impact on the capacity or kinetics, the aged material was ball milled again and then cycled. The results, shown in Figure 5, indicate that after re-milling the aged material, the hexahydride capacity was fully restored. The tetrahydride kinetics were restored and the capacity recovered to within $0.17 \mathrm{wt} \%$ of the fresh material. This indicated that much of the degradation in this sample was due to morphology changes, not contamination.

To summarize, a sample of catalyzed sodium alanates showed degradation in capacity and sorption rate after repeated hydrogen cycling. Analyses of this material showed no signs of 
hydrocarbon contamination. A small amount of oxidized sodium in the sample may contribute to capacity degradation as indicated by thermal decomposition analysis. The formation of an intermetallic Ti/AL alloy is likely to be responsible for the hydrogen capacity and kinetic degradation observed. This is supported by XRD and SEM measurements of the material. Nearly full restoration of the catalytic activity was observed by re-ballmilling, most likely facilitated by the redistribution of the titanium from the sodium-rich particles to the remaining aluminum particles. The inability to restore the remaining $0.17 \mathrm{wt} \%$ of capacity may have been caused by partial oxidation of sodium.

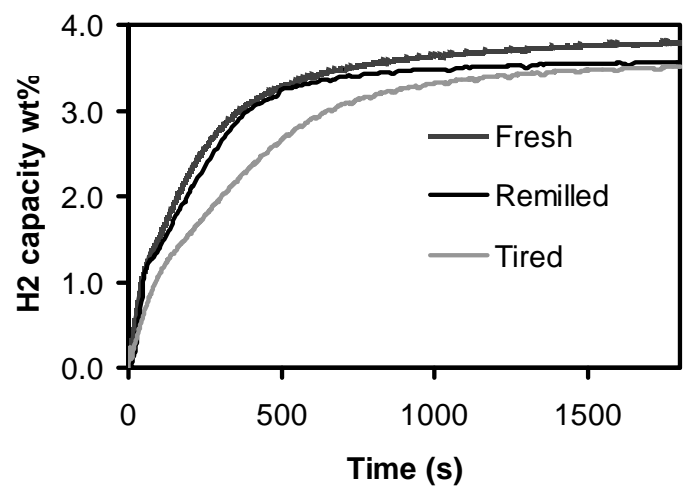

Figure 5. Relative kinetic and capacity comparison for fresh, aged, and re-milled samples undergoing 30 minute absorptions at 122 bar and $150{ }^{\circ} \mathrm{C}$

\subsection{Demonstration System}

The hydrogen storage system developed by Sandia, referred to as the Demonstration System, consists of four identical storage modules. One of these modules is shown in Figure 6. Each storage module is a shell and tube heat exchanger with sodium alanate stored in tubes enclosed within the heat exchanger shell. Twelve tubes arranged in a staggered 4 by 3 array make up each module.

Temperature control during hydrogen absorption and desorption is accomplished by circulating a heat transfer fluid through the module shell. The fluid enters one end of the module through a manifold and flows through six baffled sections before exiting at the opposite end. The baffles force the fluid into a cross-flow path to maximize heat transfer. Hydrogen enters and exits the modules through a $1 / 4$ " manifold attached to one end of the tubes. Each module has a nominal hydrogen capacity of 750 grams. 


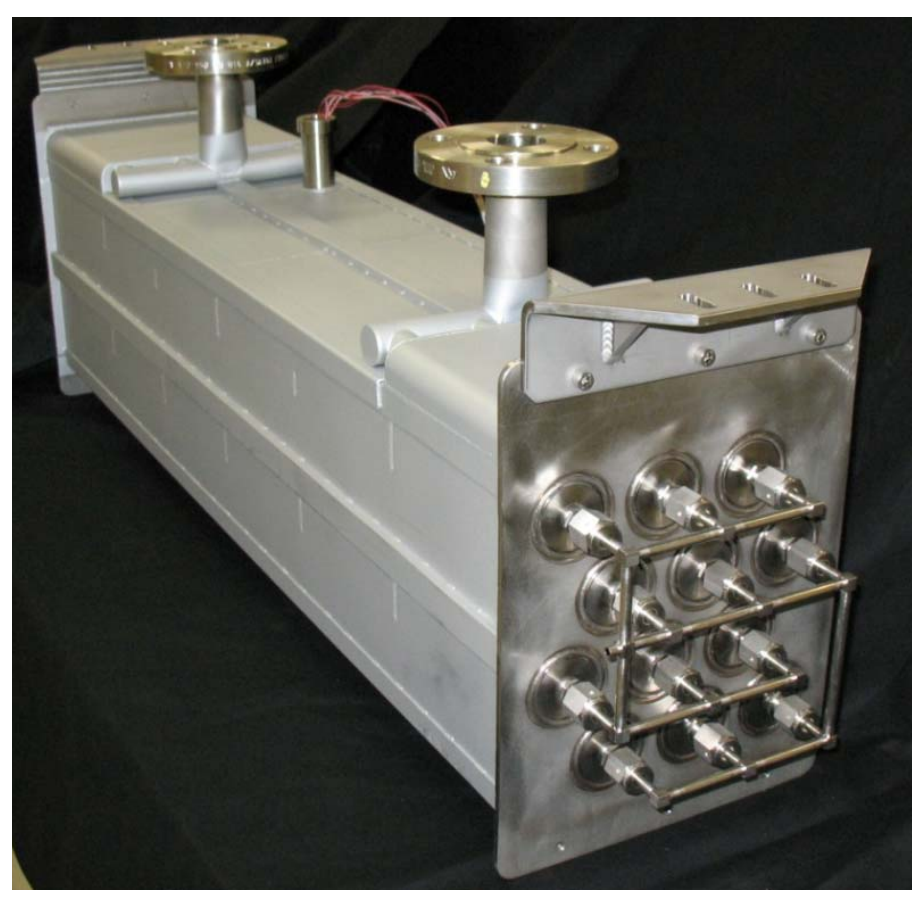

\section{Figure 6. Demonstration System hydrogen storage module.}

As shown in Figure 7, each tube has an internal diameter of 2.01" and is about 34" long. The tubes are made from 0.120 " thick $316 \mathrm{~L}$ stainless steel and are rated for a working pressure of 2000 psi hydrogen. Each tube is packed with a 9:1 sodium alanate/graphite mixture to a density of $1.0 \mathrm{~g} / \mathrm{cc}$ resulting in a mass of $1.92 \mathrm{~kg}$ of material per tube and $23.0 \mathrm{~kg}$ per module. The graphite is added to improve heat transfer by increasing the effective thermal conductivity of the mixture [3-5]. Note that these modules contain about 1000 times as much material as the small sample described in the previous section. Figure 7 shows a close up view of both ends of a tube. The hydrogen port is shown on the left. The end shown on the right was used to load the tube with sodium alanate and is sealed with a threaded plug. The plug, shown in the upper image, includes a thermocouple well for measuring the internal temperature of the material during operation.

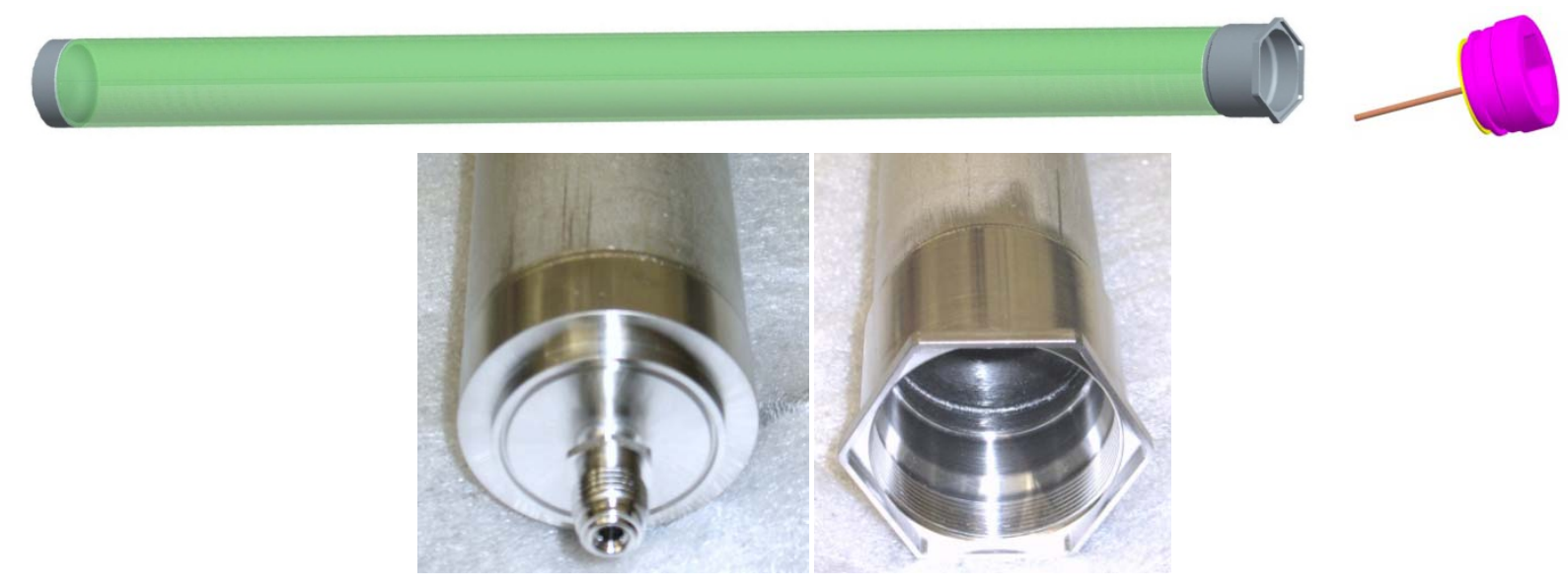

Figure 7. Solid model of module tube with end detail shown. 


\subsection{Reference cycles}

To track the hydrogen storage system capacity as the system was cycled, a specific absorption experiment was used, called the reference cycle. The reference cycle was carried out in two steps so that the kinetics and capacity for each of the alanate phases could be compared as the system aged. The fluid temperature for this cycle was set at $140{ }^{\circ} \mathrm{C}$ and kept constant. The first step of the cycle was performed at a hydrogen pressure of $800 \mathrm{psi}$. Once the hexahydride phase was completely hydrided, the pressure was increased to $2000 \mathrm{psi}$. The tetrahydride phase would then form until the test was ended after a period of $50 \mathrm{~min}$.

This cycle was different than that used for the small sample tests for a couple of reasons. First, the Demonstration System was designed with additional heat and mass transfer limitations that were not represented in the small sample. The main effect of these limitations was that the hexahydride phase could not be hydrided at hydrogen pressures above about 1000 psi due to the temperature rise within the system. Second, there was a desire to separate the hydrogenation of each phase such that the hexahydride phase would complete with no tetrahydride formation.

These reference cycles were performed periodically during the GM testing campaign with a final reference cycle taken at the end of the GM project. This was at cycle 41 to 45 depending on the module. Figure 8 shows the hydrogen capacity data from these cycles. As with the small sample data, the kinetics of both phases deminish with cycle and final capacity decreases.

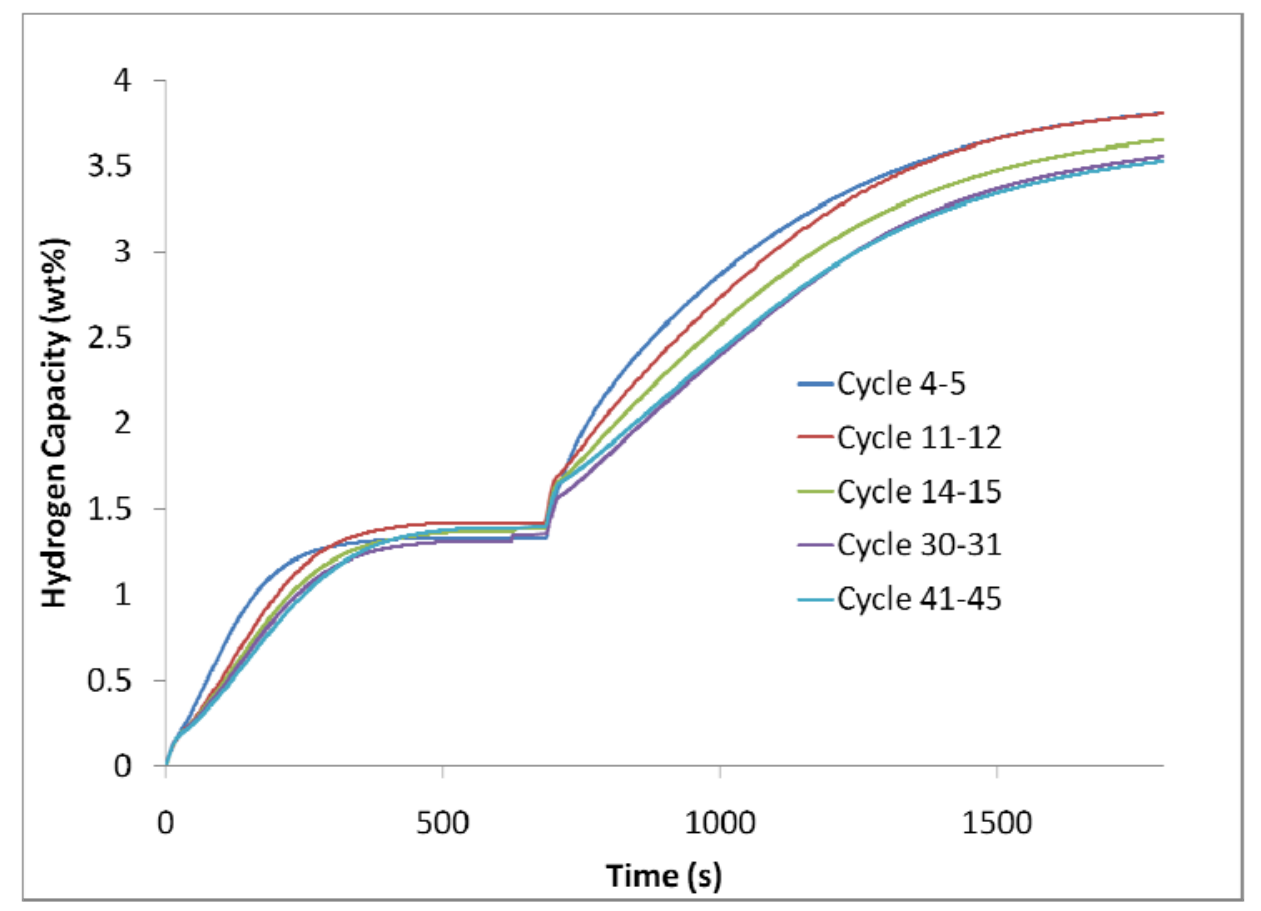

Figure 8. Reference absorption cycles run with the Demonstration System

Figure 9 shows the final hydrogen capacity for each of the reference cycles plotted against cycle number. As with the small sample data, the capacity decrease was fit with a line. The slope of 
the linear fit suggests a capacity degradation rate of about $0.007 \mathrm{wt} \%$ per cycle. Note that this is larger than the $0.003 \mathrm{wt} \%$ per cycle found for the small sample experiments with a $30 \mathrm{~min}$ duration. However, the Demonstration System material was mixed with ENG graphite for improved heat transfer. As mentioned previously, small sample testing with the graphite/alanate mixture showed a greater degradation rate of $0.010 \mathrm{wt} \%$ per cycle. So, while these results are not directly comparable to the small sample results due to the differences in the cycle procedure, they do indicate a similar degradation rate in the vehicle-scale system.

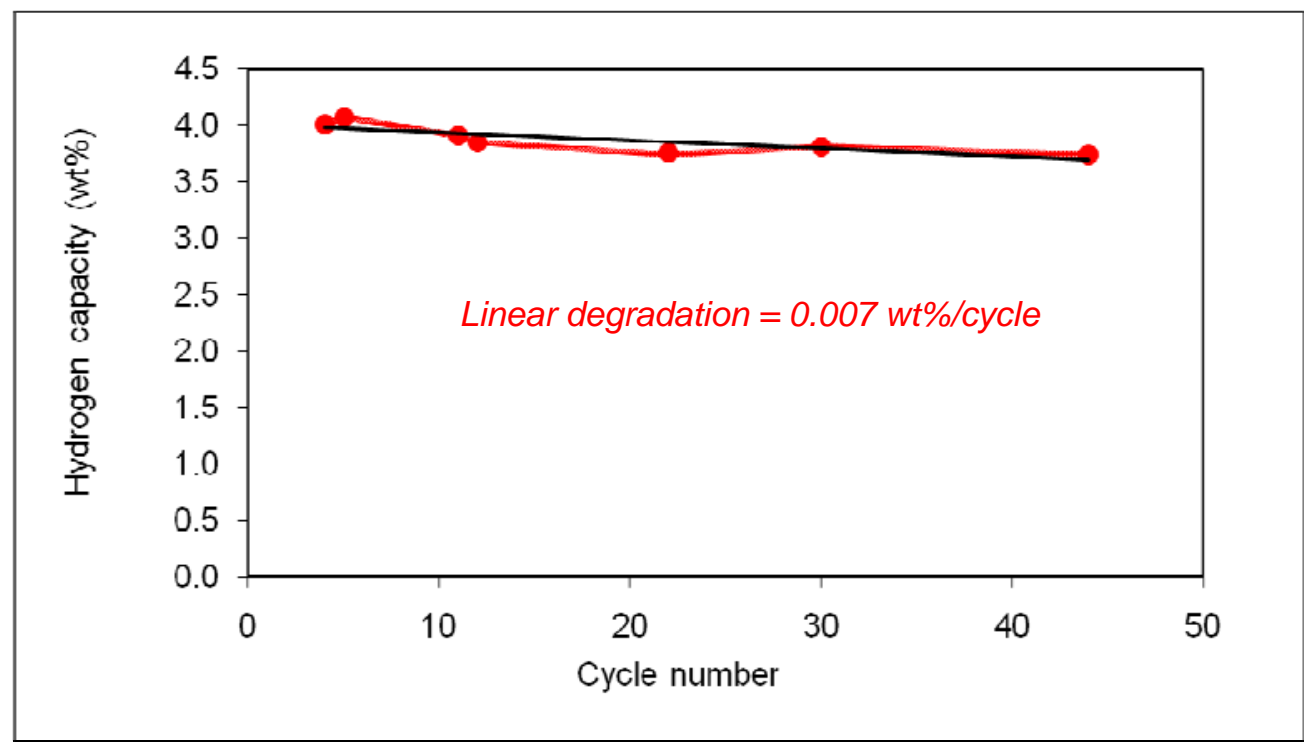

Figure 9. Demonstration System capacity degradation as a function of cycle number 



\section{DURABILITY CYCLES}

\subsection{Initial Cycles}

The goal of this work was to continue to cycle the Demonstration System to track the hydrogen storage capacity as a function of cycle number. However, rather than continue using the reference absorption, a new cycle procedure was defined that was more like the small sample cycle.

\subsubsection{Absorption Cycle Procedure}

To more closely mimic the small sample tests and limit the cycle times, the absorptions were carried out for $30 \mathrm{~min}$ at a hydrogen pressure of $2000 \mathrm{psi}$ and a coolant temperature of $150 \mathrm{C}$. As mentioned before, refueling the Demonstration System at an initial pressure above about 1000 psi results in a significant temperature rise due to fast hexahydride kinetics and limited heat transfer. To accomodate this heat transfer limitation, an automated hydrogen control scheme was employed.

This absorption control scheme consisted of using the sodium alanate temperature to trigger the opening and closing of the hydrogen inlet valve to the module. With the module at an initial temperature of $150{ }^{\circ} \mathrm{C}$, the valve is opened to the hydrogen source at 2000 psi. Once a measured sodium alanate temperature reaches a setpoint (e.g. $200^{\circ} \mathrm{C}$ ), the valve is closed. The valve is not re-opened until the temperature falls below the setpoint. The valve is thus modulated to limit the peak system temperature to a desired value.

Figure 10 shows an example absorption on the left. Capacity includes the gaseous hydrogen stored in the modules. The alanate temperature is measured using the thermocouple wells shown in Figure 7 and is the average of all tubes. The tube temperature is measured with RTD's affixed with epoxy to the outer tube wall at various locations and is the average of these measurements. Notice that a significant temperature gradient is developed from the center of the tubes to the outer wall during absorption, especially during the faster hexahydride phase. As the absorption rate decreases, this temperature gradient also decreases. 

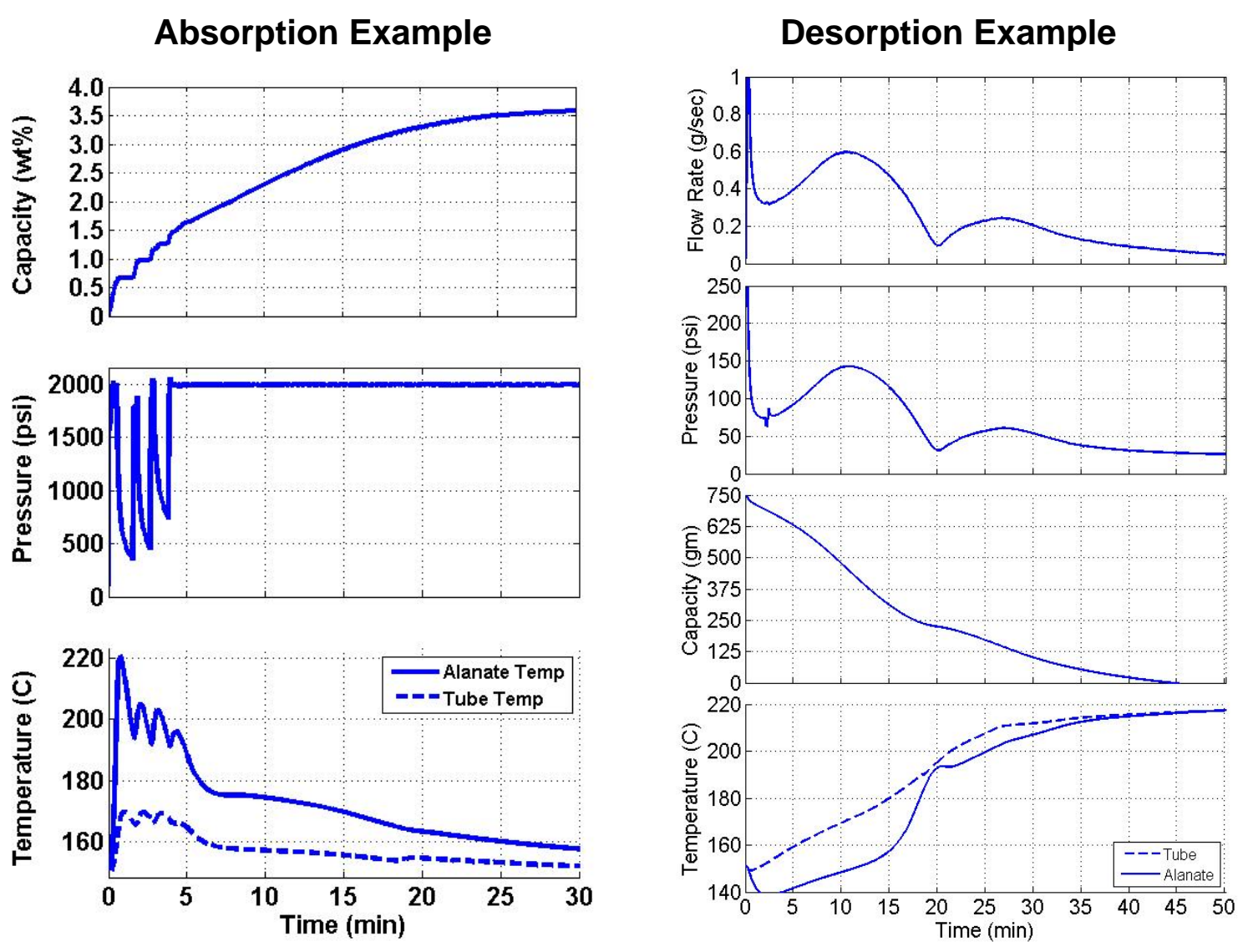

Figure 10. Example of the initial absorption and desorpton conditions used for the durability study

\subsubsection{Desorption Cycle Procedure}

The desorption thermal profiles for the durability testing were also quite similar to those of the small sample. For the Demonstration System, temperature was ramped from $150{ }^{\circ} \mathrm{C}$ to $220^{\circ} \mathrm{C}$ while desorbing to atmosphere. Like the small sample, the tetrahydride phase would disassociate completely before the temperature reached $180^{\circ} \mathrm{C}$. Once the temperature reached $220^{\circ} \mathrm{C}$ it was held until the test duration of 50 minutes was reached.

Figure 10 shows an example desorption from one module on the right. Hydrogen flow rate, shown in the top plot, varies with capacity and temperature. Pressure, shown in the second plot from the top and measured at the exit of the bed, increases to drive higher flow rates through the vent lines. About two thirds of the 750 grams of stored hydrogen comes from the tet phase while the hexahydride phase contributes the remaining third. Note in the bottom plot that tube temperature is higher than alanate temperature since the tubes are heated from the outside by oil flow. 


\subsubsection{Cycling Results}

With the short duration absorption and desorption cycles described above, the effective capacity of the modules was expected to drop during the initial cycles until it reached a quasi steady-state value. This reduced capacity was then expected to degrade at a rate similar to that found with the GM reference cycles.

Figure 11 shows the final capacity taken from the first sixteen durability cycles for one of the modules. As mentioned, the initial rapid drop in effective capacity with cycling was expected, but it was also expected to level off at a rate similar to the reference cycle degradation. As the figure shows, this was not the case. These cycles were all conducted using the previously described procedures with two exceptions. Absorption \#45 was a reference absorption run using the procedure discussed in section 1.3., and cycle \#51 was part of an investigation into the apparent capacity loss of the modules. Because these cycles were of longer duration than the durability cycles, the next cycles showed an increase in effective capacity.

The six cycles following A45 showed an almost linear decrease in capacity of more than 0.05 $\mathrm{wt} \%$ per cycle. This degradation rate was nearly an order of magnitude greater than the expected value. Since the rate of reduction of hydrogen capacity was much greater than any previous tests, we suspected that the reactivity of the sodium alanates had been somehow adversely impacted either thermally or by contamination. This prompted an investigation into possible causes which uncovered evidence of air contamination of our hydrogen supply due to a contaminated hydrogen 6-pack. This investigation will be covered in more detail in a later section. Since the contamination evidence was inconclusive, we continued to cycle the modules to track their capacity. Cycles 52-56 show continued rapid capacity loss. 


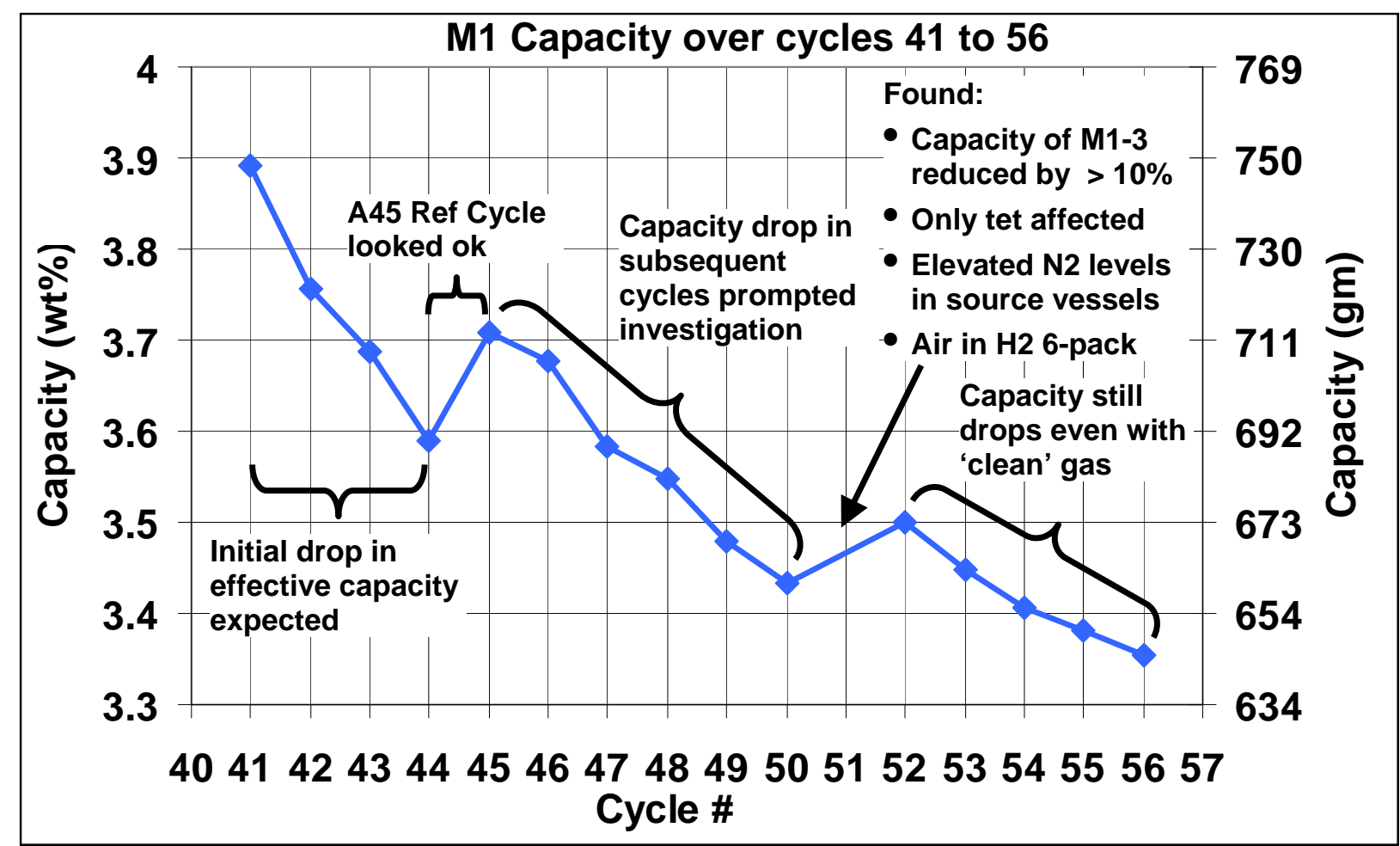

Figure 11. Rapid capacity drop during initial durability study cycles

\subsection{Final Cycles}

The cause of the rapid capacity loss during the initial durability cycles was suspected to be air contamination. However, this suspicion was not confirmed by solid evidence as will be discussed. Another potential cause was material segregation like sintering or agglomeration due to temperature. This suspicion was backed by the small sample results where a morphologyrelated effect had been found to be partially responsible for the capacity degradation.

To eliminate this potential effect, the absorption and desorption cycles were modified for the remaining durability tests. Since it is known that the tetrahydride phase melts at temperatures above $180 \mathrm{C}$, the goal was to move the operating conditions further from this point and limit peak temperatures. The modified procedures are described below.

\subsubsection{Absorption Cycle Procedure}

The new absorption cycle was only slightly different than that performed previously. For the remaining durability cycles, the initial temperature and coolant temperature were lowered from $150{ }^{\circ} \mathrm{C}$ to $140{ }^{\circ} \mathrm{C}$. The effect of this was that the peak temperature during the hexahydride phase absorption was reduced from about $230{ }^{\circ} \mathrm{C}$ to $220{ }^{\circ} \mathrm{C}$. 


\subsubsection{Desorption Cycle Procedure}

The desorption conditions were modified more significantly than the absorption cycle. The previous procedure was modeled after the small scale tests where the modules were desorbed as rapidly as possible through the vent as the temperature was ramped then held at the maximum value. However, there were several questions about this procedure. The first was if the alanate temperature was ramped too rapidly such that tetrahydride phase was near the melting temperature. The second question was if desorbing directly to the vent allowed air to backstream into the hydrogen manifold.

To address both of these questions, the new desorption procedure was more controlled and used a more protected desorption path through the hydrogen flow controller. Also, rather than ramp the temperature from $150{ }^{\circ} \mathrm{C}$ directly to $220^{\circ} \mathrm{C}$, the temperature was held constant during the entire tetrahydride phase desorption before it was increased to the hexahydride phase desorption temperature. For the tetrahydride phase, the oil temperature was set at $170 \mathrm{C}$.

During the desorptions, the operator manually controlled the flow controller setpoint to maintain an outlet module pressure of greater than 50 psi. As the uppermost plot in Figure 11 shows, tetrahydride phase desorption rates varied from $0.5 \mathrm{~g} / \mathrm{sec}$ to about $0.2 \mathrm{~g} / \mathrm{sec}$ while hexahydride phase rates varied from about $0.18 \mathrm{~g} / \mathrm{sec}$ to less than $0.05 \mathrm{~g} / \mathrm{sec}$.

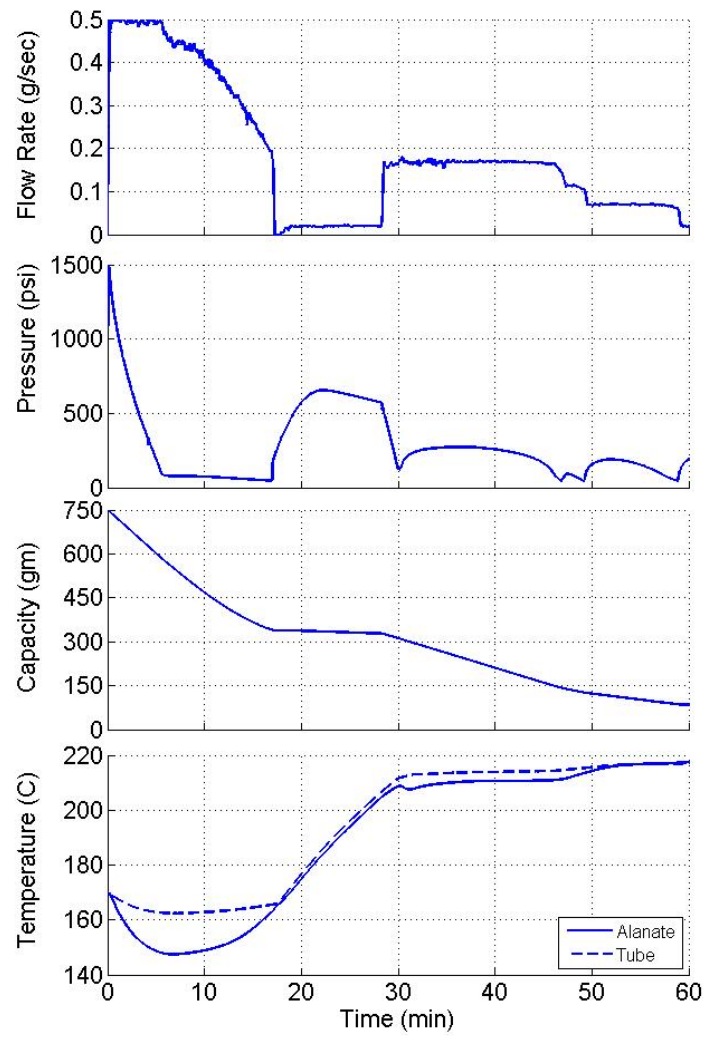

Figure 12. Example of the new desorption cycle for the durability study 


\subsubsection{Cycle Results}

Following the change in cycling procedures, Modules \#2 and \#3 were cycled another 22 times each. The final capacities for these cycles are shown in Figure 13. Note that several cycles have been removed from this plot due to inconsistencies in the data that were due to operator mistakes and hardware malfunctions. Seventeen cycle capacities are shown for each module along with a linear fit to the capacity degradation. The Module \#3 capacity loss rate was about $0.025 \mathrm{wt} \%$ per cycle, faster than the Module $\# 2$ rate at $0.020 \mathrm{wt} \%$ per cycle. Both rates are significantly greater than the $0.007 \mathrm{wt} \%$ per cycle seen during the reference cycle tests.

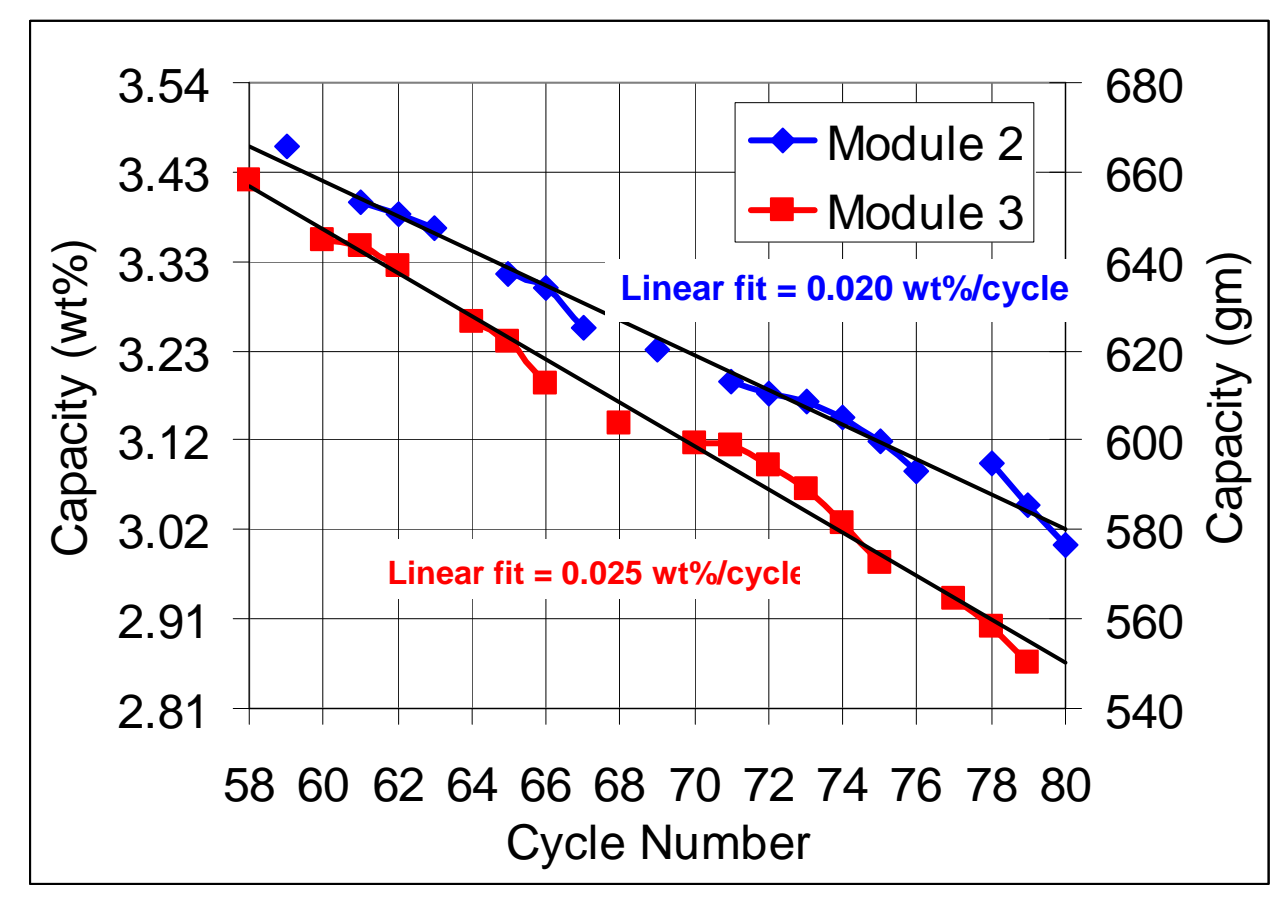

Figure 13. Capacity loss over cycles 58-80

Due to the continued drop in module hydrogen capacity, the scope of this work was modified. Rather than testing the modules to 100 cycles to determine cycle durability, we chose to halt the cycling and dismantle one of the modules to learn more about the possible contamination. To that end, Module \#3 was removed from the Demonstration System after the 79th cycle. The heat exchanger shell was removed from the module to separate out individual tubes for analysis. Tubes would be sectioned to examine chemical composition and morphology as a function of axial position. This analysis will be discussed in more detail below. 


\section{CAPACITY DEGRADATION INVESTIGATION}

Two separate investigations into the hydrogen capacity degradation were carried out during this project. The first was conducted following cycle 50 as shown previously in Figure 10. During the initial cycles, Modules 1, 2, and 3 were cycled while Module 4 was left in its then current state for other testing. Following cycle 50, a number of different tests were carried with the modules to check the relative module capacities and sorption rates. In addition, the hydrogen manifold was tested to determine the hydrogen purity in the system.

While the capacity and gas purity tests supported a potential air contamination of the three modules, we decided to continue to cycle Modules 2 and 3 to track the capacity loss further. However, by cycle 80/79 of these modules it seemed clear that the nearly linear capacity drop would continue. The second investigation into the capacity degradation was then initiated. This investigation included disassembling Module 3 to analyze the sodium alanate from individual tubes.

\subsection{Initial Investigation}

\subsubsection{Gas Purity Tests}

While testing the Demonstration System, a key step in the operating procedure was to ensure that the hydrogen manifold was free from contamination. This was accomplished through the use of an integrated residual gas analysis (RGA) system. Once the system was purged following initial assembly, the gas purity was confirmed using the RGA. After this initial gas purity analysis, any system maintenance or upgrades were followed by a purge and gas purity check prior to operation. One frequent operation was replenishing the hydrogen supply to the system which had to be performed several times per week. It was this procedure that was of primary concern for contamination which could occur due to operator error or contaminated hydrogen 6-packs. A specific procedure was developed to check the hydrogen manifold every time a new 6-pack was attached to the system. The RGA data from these gas purity checks were saved as a quality record.

This check of the hydrogen 6-packs was performed throughout the Demonstration System testing for GM as well as this durability study. One of the first steps in the initial capacity loss investigation was to review the RGA checks during the first nine cycles. However, these data showed normal results.

The next step was to sample the gas from the supply system through the hydrogen manifold feeding the modules. This test yielded an interesting result. The RGA showed a significantly elevated nitrogen level as shown in Table 1. While a 'normal' scan would usually show nitrogen at less than $50 \mathrm{ppm}$, this scan showed the value at $1,600 \mathrm{ppm}$. Since there was no other obvious source of nitrogen, this result indicated that air had been introduced into the source volumes. However, the oxygen level shown by the RGA was not elevated. Note that the elevated He level in the scan of the hydrogen supply was expected since the manifold is routinely exposed to $\mathrm{He}$ for purging. 
To confirm the RGA results, a sample of the supply system gas was sent to an outside test lab. Atlantic Analytical Laboratory in Whitehouse, NJ performed an analysis of the hydrogen supply gas and found the results shown in the last row of Table 1. Their results matched quite well with our RGA results. The fact that two independent measurements showed elevated nitrogen but not oxygen levels left a question as to whether the gas supply had been contaminated with air.

Table 1. Gas species found in hydrogen supply (ppm)

\begin{tabular}{|l|c|c|c|c|}
\hline & Water & Nitrogen & Oxygen & Helium \\
\hline 'Normal' RGA scan & $\sim 100$ & $\sim 40$ & $\sim 10$ & $\sim 40$ \\
\hline RGA scan of H2 supply & 127 & 1,600 & 28 & 230 \\
\hline Gas Analysis from AAL & 28 & 1,500 & 57 & 110 \\
\hline
\end{tabular}

After the gas purity tests, the hydrogen supply for the Demonstration System was completely purged and re-filled with fresh hydrogen. RGA checks were performed on the hydrogen 6-packs used to fill the supply cylinders as well as on the gas from the supply through the manifold. The purity of the hydrogen supply to the modules was thus verified prior to further cycling. However, one of the RGA checks showed another interesting result.

Upon sampling gas from one of the hydrogen 6-packs prior to filling the supply cylinders, the RGA showed significantly elevated levels of both nitrogen and oxygen. To compare with the values in Table 1, the nitrogen level was 3,200 ppm and the oxygen level was $430 \mathrm{ppm}$. This clearly indicated an air contaminated 6-pack and raised the question of whether this was the source of the module capacity loss. While not unambiguously certain, it seemed likely that despite the rigor dedicated to qualifying the purity of the hydrogen, contaminated gas was still introduced into the system and led to the capacity degradation.

\subsubsection{Capacity and Sorption Rate Tests}

Following cycle \#50, several cycling tests were performed to characterize the sorption rate and capacity of each module individually. One goal of this testing was to compare Modules \#1, \#2, and \#3 with Module \#4 which had not been cycled with the others. The first of these cycles was a reference cycle absorption preceded and followed by extended desorptions to drive off all of the stored hydrogen. Table 2 shows this data compared to a similar set of cycles performed during the GM testing. Note that only desorption data includes individual module capacities. During absorption tests, the hydrogen flow to all modules passes through a single flow meter so only a combined capacity is available. Note also that throughout our testing the absorption flow meter measured lower capacities than the combined desorption flow meters. It is believed that this is due to the low end accuracy and resolution of the absorption flow meter which does not capture the slow rates at the end of refueling tests. The desorption capacities are therefore used to compare capacities while the absorption values are shown just for reference.

The average total capacities shown in Table 2 indicate that the system capacity dropped by about 140 grams between cycle 31 and cycle 51 . However, if the individual module values are considered, Modules 1, 2, and 3 dropped about 60 grams each while Module 4 increased by 
about 40 grams. Since there is no reason for the actual capacity to increase, it is likely that the later desorption cycles were taken to a greater level of completion. Despite a few discrepancies, the two sets of data point to several conclusions. First, the drop in effective capacity seen in the first nine durability cycles is reflected in the extended absorption and desorption cycles. Second, the three modules cycled for the durability study have a significantly lower capacity than the module not cycled. Lastly, each of the three modules lost a similar amount of hydrogen capacity.

Table 2. Comparison of module capacities before and after capacity loss

\begin{tabular}{l|llll|l} 
& M1 & M2 & M3 & M4 & Total \\
D30 & 766 & 776 & 778 & 767 & $\mathbf{3 0 8 7}$ \\
A31 & & & & & $\mathbf{2 9 3 3}$ \\
D31 & 734 & 825 & 764 & 764 & $\mathbf{3 0 8 7}$ \\
Average & $\mathbf{7 5 0}$ & $\mathbf{8 0 0}$ & $\mathbf{7 7 1}$ & $\mathbf{7 6 6}$ & $\mathbf{3 0 8 7}$ \\
D50 & 692 & 730 & 717 & 800 & $\mathbf{2 9 3 9}$ \\
A51 & & & & & $\mathbf{2 9 0 0}$ \\
D51 & 689 & 737 & 716 & 804 & $\mathbf{2 9 4 6}$ \\
Average & $\mathbf{6 9 0}$ & $\mathbf{7 3 4}$ & $\mathbf{7 1 7}$ & $\mathbf{8 0 2}$ & $\mathbf{2 9 4 3}$
\end{tabular}

To look more closely at the individual module rates and hydrogen capacity, each module was cycled individually using an identical procedure for absorption and desorption. Data from these tests is shown in Figure 13. The absorption tests, shown on the left, were performed with a twostep pressure profile. Hydrogen pressure was increased from 1100 psi to 2000 psi once the hexahydride phase was completely hydrided. This way each phase could be examined separately. The data shows that Module \#4 had both faster sorption rate and obtained a higher capacity over the 45 minute test than the other three modules. This is reflected in the temperature data which shows a steeper increase and higher peak value during the hexahydride phase absorption as well as a higher sustained value during the tetrahydride phase absorption.

The desorption tests, shown on the right, were performed in two steps as well. Temperature was the control parameter for these tests. The tetrahydride phase was desorbed with a constant oil temperature of $175 \mathrm{C}$. Once this phase was completely dehydrided, the temperature was increased to $220 \mathrm{C}$ and the hexahydride phase was desorbed. The initial desorption rate for the M4 tetrahydride phase is about the same as that of the other three modules, but both the capacity and temperature plots show that the rate is sustained for much longer resulting in a significantly higher capacity. Compared to modules M2 and M3, the M4 hexahydride desorption rate and capacity were nearly identical, although this is difficult to tell from the plot due to the offset in the curves. Module M1 hexahydride rate and capacity were reduced compared to the other three modules. The final capacities were similar to those shown for D50 and D51 in Table 2. 

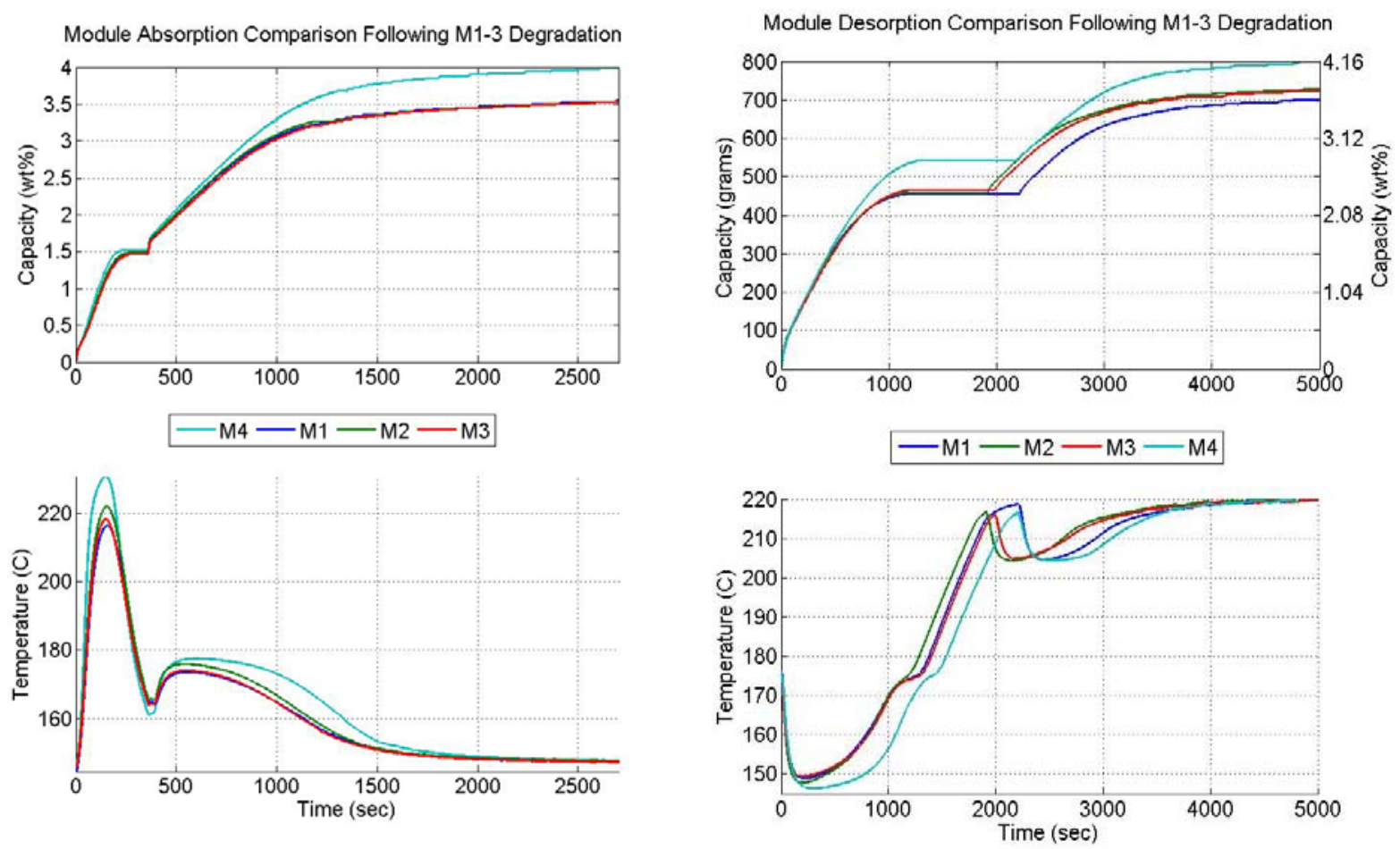

Figure 14. Module capacity and kinetics comparison following initial durability cycles

The final capacity check that was performed was meant to characterize the ultimate capacity of the modules. To do so, an extended absorption test was run to compensate for slow sorption rate. All four modules were hydrided for about six hours at $2000 \mathrm{psi}$ and $150 \mathrm{C}$. The modules were then desorbed in two steps like before with an initial oil temperature of $170 \mathrm{C}$ and a final oil temperature of $220 \mathrm{C}$. This cycle was number 57 for M1 and M3, 58 for M2, and 47 for M4. The desorption results were used to compare the capacity of both alanate phases of all four modules.

The results are shown in Table 3. For these results, the gaseous hydrogen in the modules at the start of the desorption was accounted for so that the actual material capacities could be compared. Compared to Table 2 capacities, Table 3 shows that all of the modules achieved a higher capacity with the extended refueling time. With the gaseous hydrogen accounted for, the results show that M2, M3, and M4 were able to reach close to maximum capacity, but that M1 reached only about $90 \%$ capacity for both the hexahydride and tetrahydride phases.

Table 3. Comparison of module capacities following extended absorption

\begin{tabular}{|l|c|c|c|c|}
\hline & M1 & M2 & M3 & M4 \\
\hline Total $\mathbf{H}_{\mathbf{2}} \mathbf{( g m )}$ & 738 & 812 & 803 & 825 \\
\hline Gaseous $\mathbf{H}_{\mathbf{2}} \mathbf{( g m )}$ & 57 & 59 & 60 & 64 \\
\hline Tet Phase $\mathbf{H}_{\mathbf{2}} \mathbf{( g m )}$ & 454 & 495 & 496 & 510 \\
\hline Hex Phase $\left.\mathbf{H}_{\mathbf{2}} \mathbf{( g m}\right)$ & 227 & 258 & 247 & 251 \\
\hline Total Solid $\mathbf{H}_{\mathbf{2}} \mathbf{( g m )}$ & 681 & 753 & 743 & 761 \\
\hline
\end{tabular}


The data in Tables 2 and 3 and Figure 13 suggested several conclusions. The results for Module 1 suggested that about $10 \%$ of the reactive material was unable to be hydrided. It seemed likely that the Na-containing material was oxidized due to contamination of the gas stream although this contamination had not been proven. However, since Modules 2 and 3 were able to be fully hydrided, it seemed unlikely that they had been contaminated in the same way. Instead, the test results showed reduced sorption rate as compared to Module 4, especially for the tetrahydride phase. This suggested the possibility of a different degradation mechanism than for Module 1 . We know that the alanate kinetics can be affected by aluminum availability, catalyst loading, and morphology. Changes in any one of these could slow kinetics without reducing capacity.

The difference between M1 and the other two modules that were part of the initial durability testing was unexpected. The three modules were exposed to the same test conditions and all showed a loss in cycle capacity. A common cause seemed likely. However, no other nondestructive diagnostics were available so further investigation at this point was not pursued.

\subsection{Final Investigation}

Subsequent cycling of Modules 2 and 3 following the initial capacity degradation investigation resulted in a nearly linear decrease in effective capacity as shown in Figure 13. Rather than spend more resources on further cycles, we decided to investigate the capacity loss by analyzing the alanate in one of the modules. To do so, the module had to be disassembled to remove and section individual tubes. Module 3 was chosen for this final capacity degradation investigation. In parallel, Module 2 was cycled a final time to determine a final ultimate capacity. The results of these tests will be discussed below.

\subsubsection{Final Capacity}

A final capacity check was performed on Module 2 to characterize the ultimate capacity of the module following the repeated cycling. As with cycle 58 discussed previously, an extended absorption test was run first. The module was then desorbed in two steps like before with an initial oil temperature of $170 \mathrm{C}$ and a final oil temperature of $220 \mathrm{C}$. This was cycle 81 for Module 2. The desorption results are listed in Table 5 along with those from cycle 58 . With the gaseous hydrogen accounted for, the results show that the cycle 81 hexahydride phase capacity was unchanged but the tetrahydride phase capacity was lower by about $10 \%$.

Table 4. M2 capacity following repeated cycling

\begin{tabular}{|l|c|c|}
\hline & Cycle 58 & Cycle 81 \\
\hline Total $\mathbf{H}_{\mathbf{2}} \mathbf{( g m )}$ & 812 & 755 \\
\hline Gaseous $\left.\mathbf{H}_{\mathbf{2}} \mathbf{( g m}\right)$ & 59 & 49 \\
\hline Tet Phase $\mathbf{H}_{\mathbf{2}} \mathbf{( g m )}$ & 495 & 445 \\
\hline Hex Phase $\mathbf{H}_{\mathbf{2}} \mathbf{( g m )}$ & 258 & 261 \\
\hline Total Solid $\left.\mathbf{H}_{\mathbf{2}} \mathbf{( g m}\right)$ & 753 & 706 \\
\hline
\end{tabular}




\subsection{2. $\mathrm{CO}_{2}$ Treatment and Disassembly}

Prior to removing the Module 3 shell, a procedure was performed in order to react any potentially unstable oxides that might have formed from air or moisture contamination. Using a process developed earlier in the program [6], the module was exposed to a 25 psi overpressure of $\mathrm{CO}_{2}$ for a period of about one hour. If sodium alanates had been exposed to air or moisture and oxidized, $\mathrm{CO}_{2}$ would react with the oxides and form carbonates that are much more stable materials. This reduced the risk that the act of cutting open the hydrogen storage vessels would cause a rapid, energetic decomposition of the unstable oxides.

The reaction with $\mathrm{CO}_{2}$ and oxidized alanates is exothermic. So, after the $\mathrm{CO}_{2}$ was connected to the gas inlet of the module, we observed a temperature rise near the gas inlet end of the module. A handheld thermocouple and an infrared camera were used to monitor the temperature. An IR image is shown below in Figure 15; the thermal insulation has been removed from the shell and the oil has been drained. The tubes are positioned very near to the shell so the temperature indicated by the IR camera should reflect the skin temperature of the tubes with reasonable fidelity. The temperatures of the tube ends rose to nearly $70 \mathrm{C}$, which is close to the equilibrium temperature for the carbonate reaction at the applied pressure. However, as the IR image indicates, the reaction seemed restricted to the first several inches of the tubes. Nevertheless, the reaction with $\mathrm{CO}_{2}$ indicated that at least some fraction of the sodium alanate was oxidized.

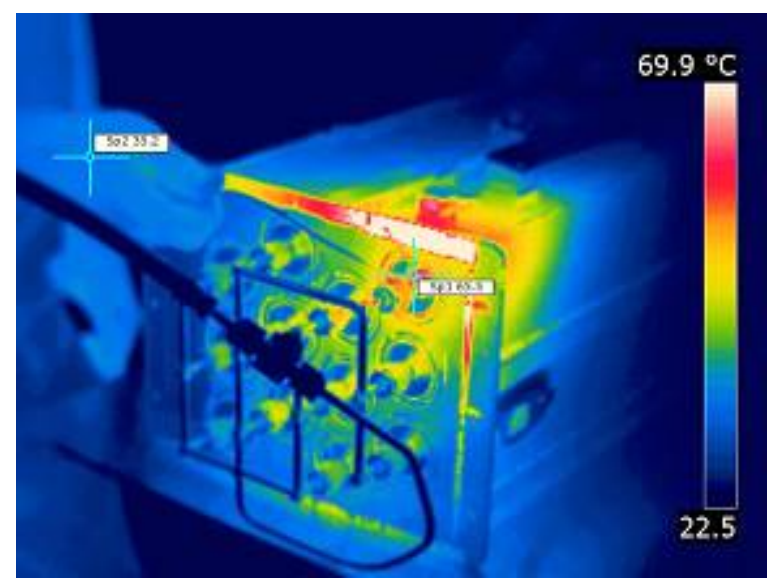

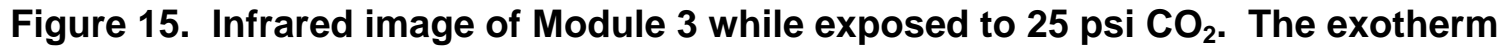
suggests carbonate formation from oxidized alanates.

Following the $\mathrm{CO}_{2}$ treatment, the module was prepared for the shell removal process. The shell was removed by systematically grinding off the welds holding the shell together. Then the module end plates were removed by a similar method. The twelve tubes were then successfully separated from the assembly and transferred into a glove box for storage. Several pictures of the shell removal process are shown in Figure 16. 

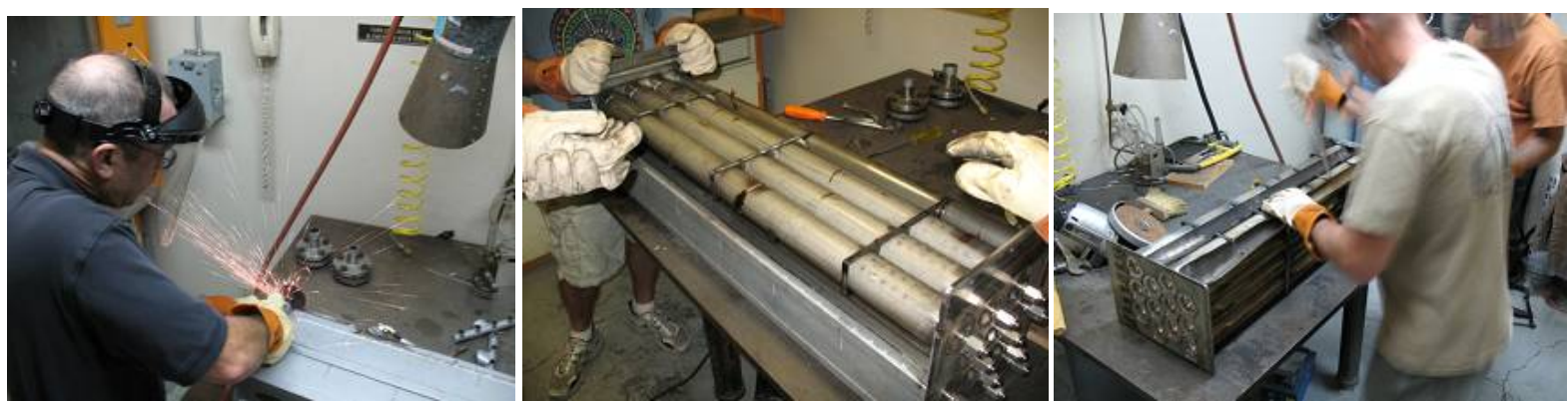

Figure 16. Removal of the Module \#3 heat exchanger shell to separate individual tubes containing the sodium alanate.

Once in the glove box, two tubes were selected for sectioning. Prior to sectioning, the tubes were subjected to a final $\mathrm{CO}_{2}$ treatment to insure that all oxides had been reacted. This $\mathrm{CO}_{2}$ treatment turned out to be necessary as Figure 17 shows. The elevated temperature in the middle section of the tube shows that this material still contained unconverted oxides. The last quarter of the tube showed no reaction to the $\mathrm{CO}_{2}$ indicating that the oxidation did not reach the far end of the tube.

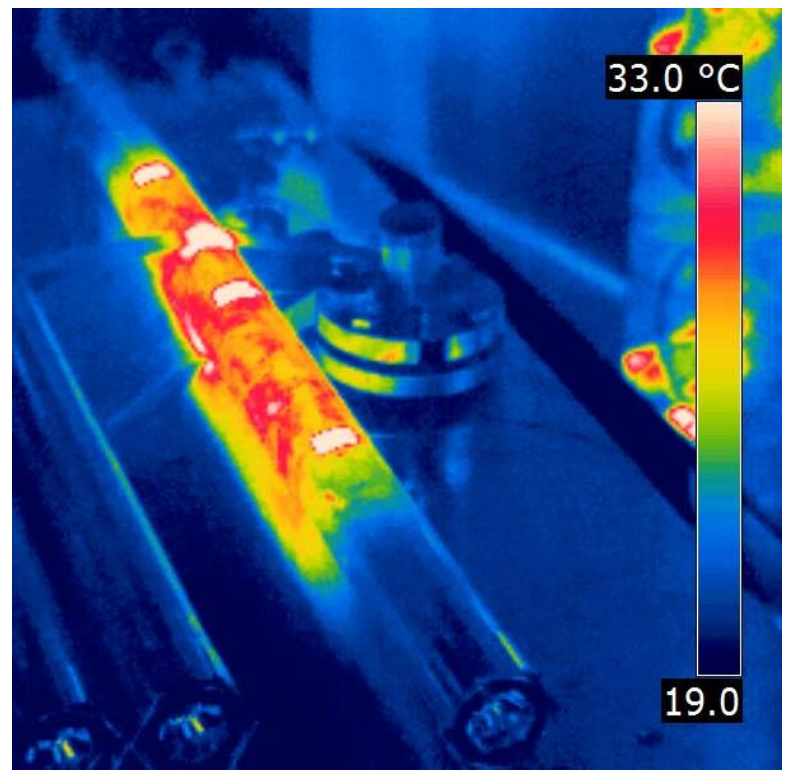

Figure 17. Infrared image of a module tube during a final $\mathrm{CO}_{2}$ treatment.

After the final $\mathrm{CO}_{2}$ treatment was complete, the tubes were transferred back to the glove box. In the inert environment, the tubes were cut into sections of six to eight inches in length. The sodium alanate had sintered into a solid cylinder over most of the length and shrunk away from the inner wall of the tubes. This allowed the hydride to be removed in individual pieces. The sodium alanate sections were then measured and catalogued. Pictures of a sectioned tube are shown below in Figure 18. 

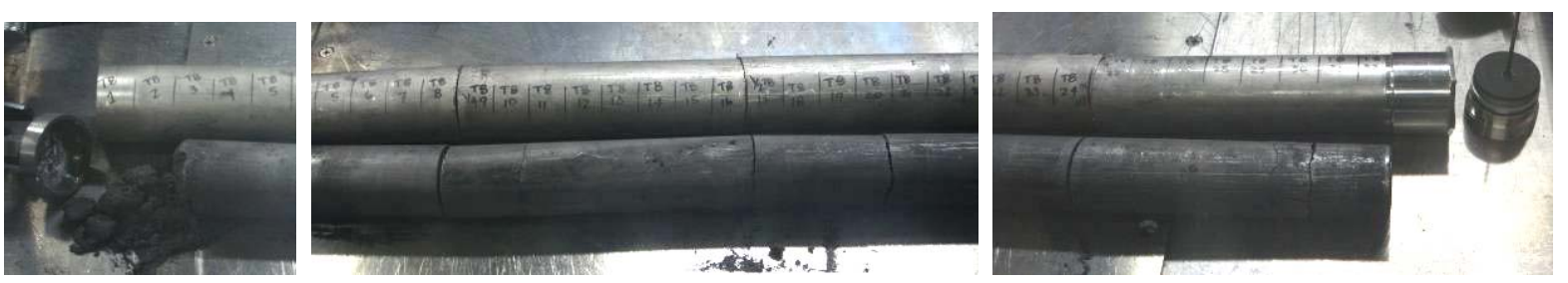

Figure 18. A sectioned tube from Module 3 with the sodium alanate removed.

Although the thermal response of the module during the $\mathrm{CO}_{2}$ treatments suggested a significant amount of oxidation, there was not a strong indication of this from the physical appearance of the sodium alanate. The catalyzed material is a dark grey, nearly black powder. The material that was removed from the tubes appeared much the same as it had when it was initially loaded, aside from the fact it was no longer a loose powder. With no visual indication of contamination, we would rely on material analysis. Material samples from several axial locations were taken from the tubes for XRD and TGA-MS analysis.

\subsubsection{X-ray Diffraction}

Measurements using a Scintag XDS 2000 powder diffractometer were performed on samples from each of 4 regions in the bed. Results are shown in Figure 19. In general, each of the samples downstream of the inlet had very similar characteristics: Clean diffraction patterns with minimal evidence of contamination. Some hexahydride is present in these regions away from the inlet/outlet of the bed, which is expected since these regions see the highest pressure during desorption.

More interestingly, the sample near the inlet (black curve in Figure 19) demonstrated significant differences in crystallography compared to the other samples. Although the patterns are difficult to quantify, some broadening is observed and some unidentified spectra are measured. This may indicate that the majority of the contamination was experienced in the entrance area. This is consistent with the $\mathrm{CO}_{2}$ treatment that indicated the highest reaction at the entrance of the module tubes. 


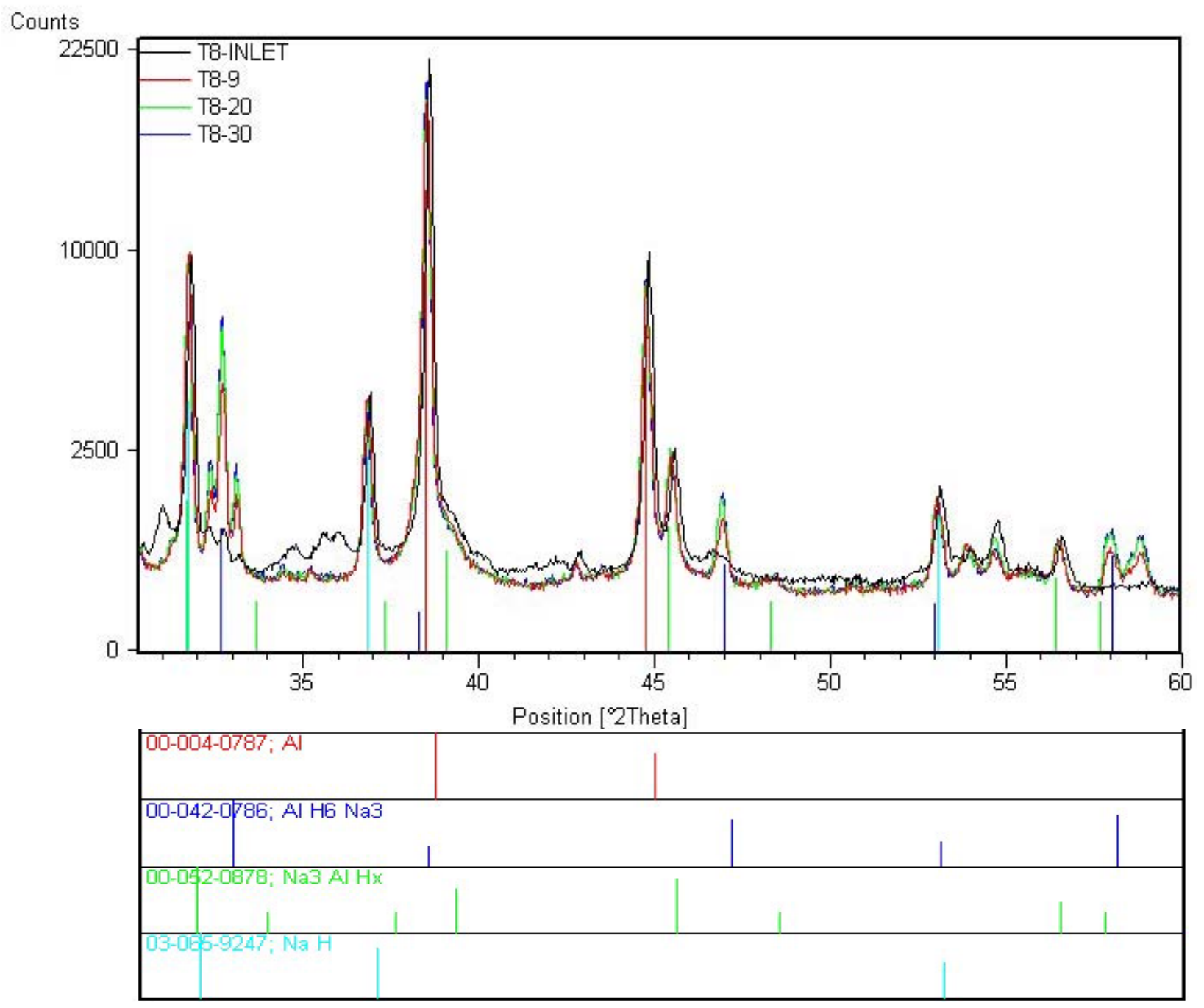

Figure 19. XRD powder diffractometry indicated that only the sample near the inlet had measurable crystallographic changes

\subsubsection{Thermo-gravimetric Analysis with Mass Spectrometry}

Measurements to quantify the evolution of gases from the samples during decomposition were performed using the Simultaneous Thermogravimetric Modulated Beam Mass Spectrometer (STMBMS) at Sandia. The measurements involve heating a sample contained in a Knudsen cell under vacuum to produce a molecular beam that is characterized with a quadrupole mass spectrometer[7,8]. Measured signals provide information on the quantity and the evolution rate of volatiles. We utilized this capability to quantify the composition of the contaminated sodium alanates. Experiments were conducted on sodium alanate samples taken from four locations in the GM module tube. The samples were taken from the reactor as a function of distance from the gas inlet and corresponded to the locations measured with XRD at distances of 0, 10, 20, and 30 inches from the reactor inlet. In each experiment the samples were heated from room temperature to $300^{\circ} \mathrm{C}$ at $2^{\circ} \mathrm{C} / \mathrm{min}$. Lowest confinement Knudsen cell conditions $(\sim 1000 \mu \mathrm{m}$ 
orifice diameters) were used for each experiment, which allows species to be measured as they evolve from the solid sample with little chance for interaction in the gas phase within the cell.

The rate of hydrogen evolution can be divided into two general regions for each experiment. One region represents the evolution of hydrogen between 100 and $200^{\circ} \mathrm{C}$ (Region 1), which is characteristic of hydrogen evolution from Ti-catalyzed sodium aluminum tetrahydride $\left(\mathrm{NaAlH}_{4}\right)$ and hexahydride $\left(\mathrm{Na}_{3} \mathrm{AlH}_{6}\right)$. The second region represents the evolution of hydrogen between 200 and $280^{\circ} \mathrm{C}$ (Region 2), which is characteristic of hydrogen evolution from uncatalyzed hexahydride. After this point, sodium begins to evolve from the sample due to the decomposition of the $\mathrm{NaH}$. The relative amount of $\mathrm{H}_{2}$ that evolves in each region changes as a function of location in the reactor bed. In the sample taken from the reactor inlet, the amount of $\mathrm{H}_{2}$ that evolves in the first region is greater than the second region. As the distance from the sample inlet increases, the amount of $\mathrm{H}_{2}$ evolved from Region 1 decreases and the amount of $\mathrm{H}_{2}$ from Region 2 increases. In the sample taken farthest from the inlet the amount of $\mathrm{H}_{2}$ that evolves from the second region is greater than the first region. This is in agreement with the XRD measurements that indicated the presence of residual hexahydride in the regions farthest from the inlet/outlet.

Results indicate that residual uncatalyzed $\mathrm{Na}_{3} \mathrm{AlH}_{6}$ exists in the inaccessible regions of the bed. This may be due to selective deactivation of the Ti-catalyst due to morphology changes or contamination. Behavior of the inlet sample is unique, and indicates that residual catalyzed $\mathrm{Na}_{3} \mathrm{AlH}_{6}$ may be present - or some other compound with available hydrogen that we have not identified. Regardless, the unique inlet sample behavior is consistent with the XRD results and the observation of increased reactivity with $\mathrm{CO}_{2}$, as discussed above.

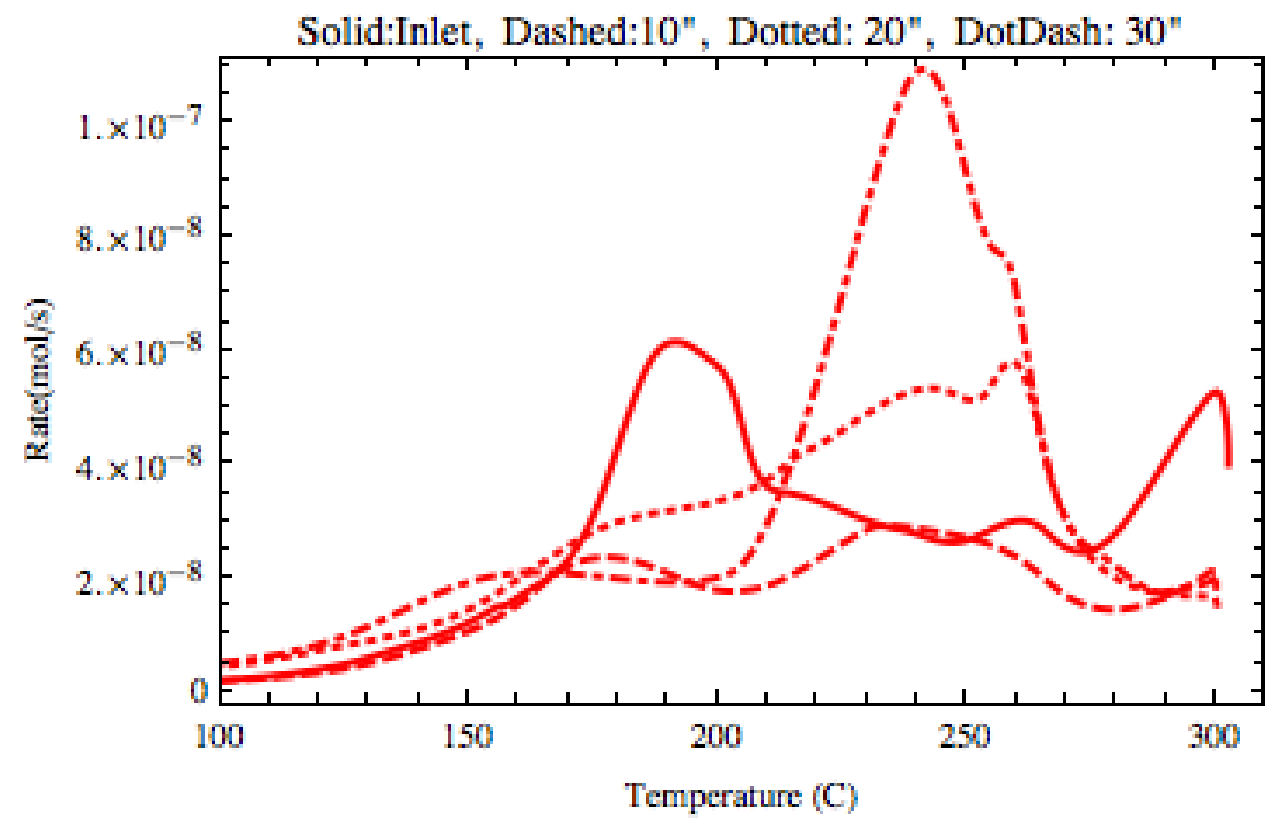

Figure 20. Comparison of the rate of evolution of $\mathrm{H}_{2}$ taken from four regions in the reactor. Results indicate that residual uncatalyzed $\mathrm{Na}_{3} \mathrm{AlH}_{6}$ exists in the inaccessible areas of the bed. 


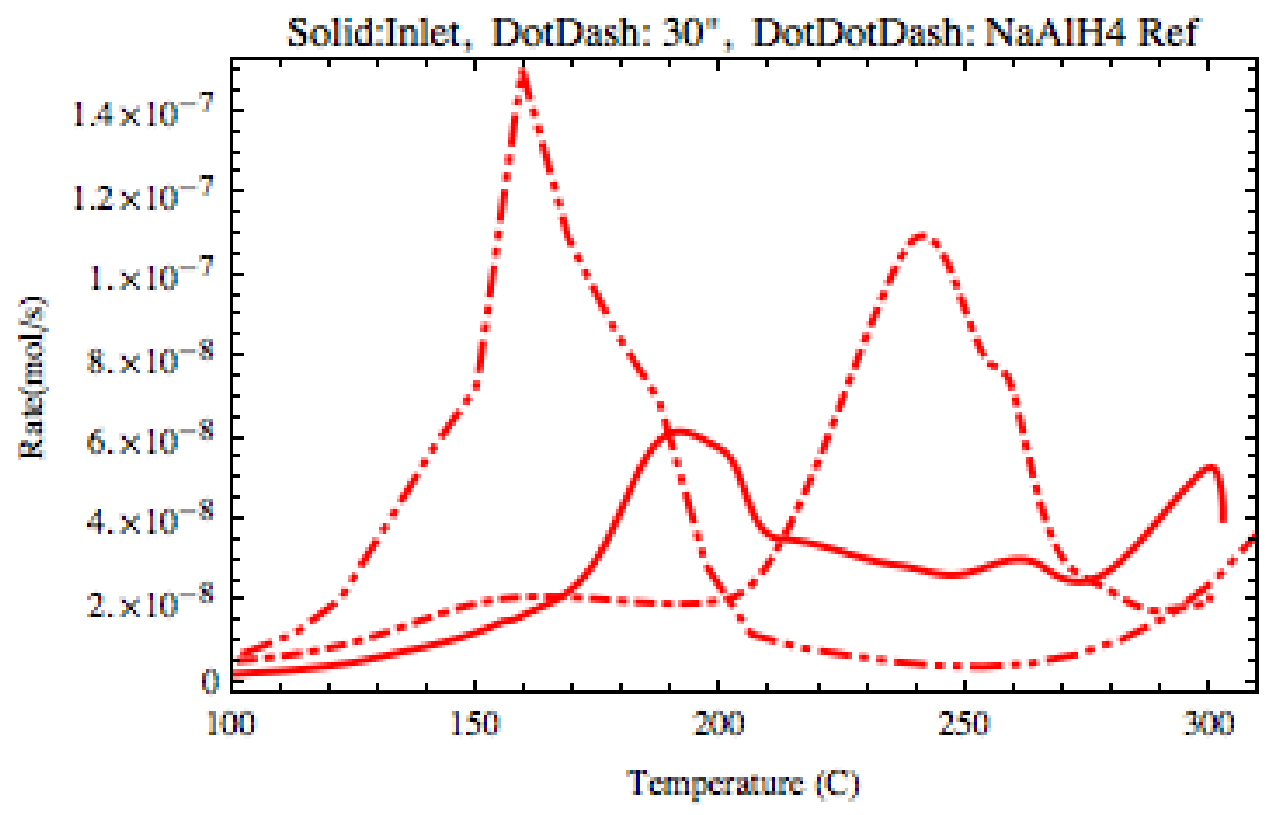

Figure 21. Comparison of the rate of evolution of $\mathrm{H}_{2}$ from the decomposition of Ticatalyzed NaAlH4 (dotdotdash) with the catalyzed samples taken from the inlet and far end of the reactor. Results indicate the presence of uncatalyzed $\mathrm{Na}_{3} \mathrm{AlH}_{6}$ in the far end and possibly the presence of catalyzed $\mathrm{Na}_{3} \mathrm{AlH}_{6}$ in the inlet sample.

In addition, the amounts of $\mathrm{H}_{2}$ and $\mathrm{CO}_{\mathrm{x}}$ that evolve from the samples are indicative of the extent of oxidation in the bed. As described above, the bed was treated with $\mathrm{CO}_{2}$ to evaluate the presence of sodium oxides and hydroxides. These materials will react with $\mathrm{CO}_{2}$ to form sodium bicarbonate. In the sample taken at the gas inlet ( 0 inches), a small amount of $\mathrm{CO}_{2}$ evolves between 75 and $150^{\circ} \mathrm{C}$ and $\mathrm{CO}$ evolves between 250 and $300^{\circ} \mathrm{C}$. Interestingly, correlated signals at $\mathrm{m} / \mathrm{z}$ values of 31 and 32 suggest that $\mathrm{CH}_{3} \mathrm{OH}$ may evolve from the sample between 70 and $130^{\circ} \mathrm{C}$. The origin of the $\mathrm{CH}_{3} \mathrm{OH}$ is unknown; however, it indicates that the graphite flake participates chemically in either the oxidation reaction, the $\mathrm{CO}_{2}$ treatment reaction, or during thermal decomposition. Since the $\mathrm{CO}_{\mathrm{x}}$ is mainly observed in the inlet sample, it can be concluded that the majority of the sodium contamination occurred near the inlet of the module tubes. 


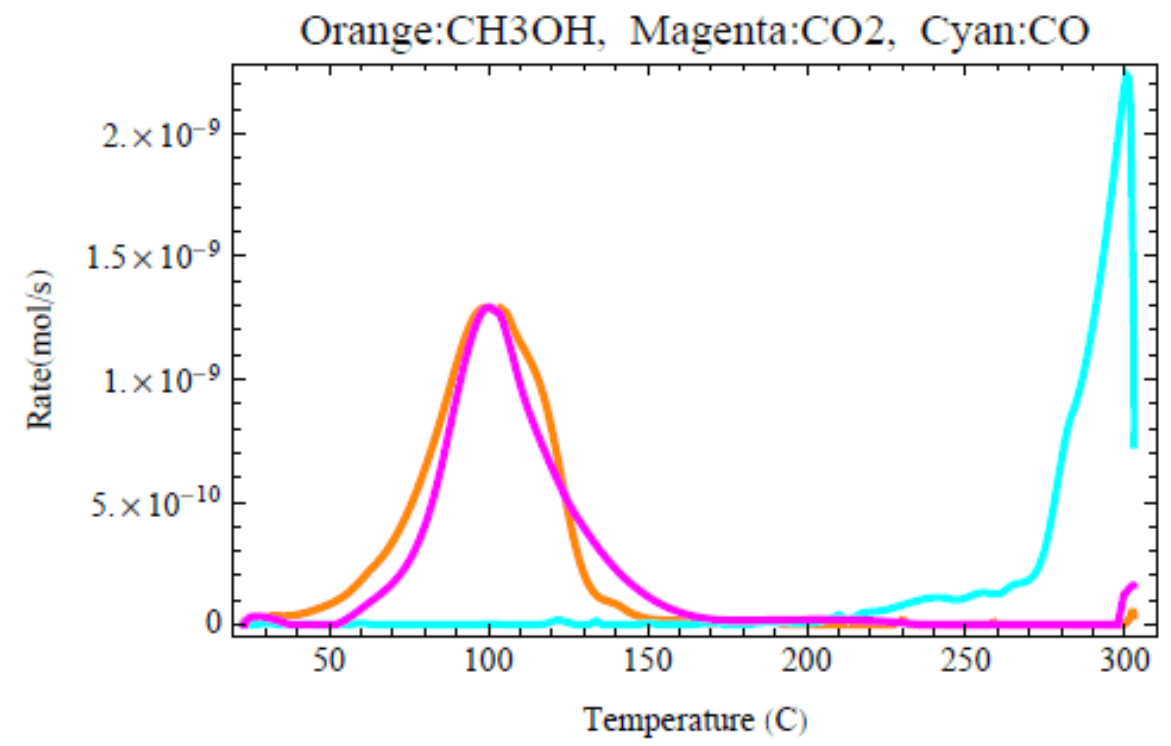

Figure 22. The sample near the inlet indicates significant amounts of $\mathrm{CO}_{\mathrm{x}}$ evolving during heating. This is a result of the $\mathrm{CO}_{2}$ treatment process, which produces sodium bicarbonate

In an effort to quantify the degree of oxidation, one additional experiment was run in which $3.0 \mathrm{mg}$ of $\mathrm{NaHCO}_{3}$ was mixed with $65 \mathrm{mg}$ of a sample taken from the inlet region. This allows comparison of the amount and temperature range of the $\mathrm{CO}_{2}$ evolution from the inlet sample with a known amount of sodium bicarbonate placed in the reaction cell. The $\mathrm{CO}_{2}$ signal from the experiment with the added sodium bicarbonate was over 100 times larger than the $\mathrm{CO}_{2}$ signals from the inlet sample by itself. In the sample from the inlet by itself the $\mathrm{CO}_{2}$ evolves between 70 and $150^{\circ} \mathrm{C}$. In the experiment with the added $\mathrm{NaHCO}_{3}$, the $\mathrm{CO}_{2}$ and $\mathrm{H}_{2} \mathrm{O}$ evolve between 100 and $175^{\circ} \mathrm{C}$. This suggests that the $\mathrm{CO}_{2}$ that evolves from the sample inlet does not evolve from pure $\mathrm{NaHCO}_{3}$ in the sample. It also suggests that if the $\mathrm{CO}_{2}$ is due to the evolution of sodium bicarbonate trapped in the sample, this would be equivalent to approximately $30 \mu \mathrm{g}$ of $\mathrm{NaHCO}_{3}$ in the $65 \mathrm{mg}$ sample, about $0.05 \mathrm{wt} \%$ or $0.03 \mathrm{~mol} \%$.

The actual capacity degradation observed in the bed was nearly $10 \%$ of the starting hydrogen capacity. Based on the assumption that each mole of sodium bicarbonate originated from one mole of sodium oxide, we would expect to see that nearly $10 \mathrm{~mol} \%$ of the sodium was oxidized and subsequently converted into sodium bicarbonate upon $\mathrm{CO}_{2}$ treatment, but this was not observed. In reality, it is likely that the contamination process is much more complex; the aluminum, and titanium are also reactive with oxygen and water and the impact of partial oxidation on these components is unknown. Evidence for this is shown in section 3.1.2, Table 3, where the actual capacity loss in module 3 was low, and the effective capacity loss therefore stems largely from reduced absorption rates. More research is required to understand the contamination process. This could explain the differences between the actual capacity degradation and the measured composition of the bed. In addition, spatial gradients in bed composition were not investigated - which provides some uncertainty. 
Nevertheless, these studies suggest that the majority of the contamination occurred near the inlet of the module tube providing more evidence that the capacity degradation was due to the contamination event. 



\section{SUMMARY AND CONCLUSIONS}

Long term lifecycle behavior of metal hydride systems has been largely unexplored in the literature. This research program gathered valuable data in the area of capacity and sorption rate performance degradation of large and small-scale complex metal hydride containing systems. Gradual performance degradation is expected during the lifecycle of the hydrogen storage system due to contamination or morphological changes within the solid matrix.

Despite rigorous experimental procedures, larger than expected degradation was observed due to a single uncharacterized event during this research effort. Seeing an opportunity to learn about the cause and effect of performance degradation during the lifecycle of systems, we performed a series of qualitative and quantitative studies to investigate the mechanisms involved.

Cycling studies indicated a rate of uniform capacity loss nearly an order of magnitude greater than control measurements. Analysis of the gas supply system showed some, but not conclusive, evidence of air contamination. Capacity experiments showed that one hydrogen storage module had a permanent $10 \%$ capacity loss in both alanate phases that would be consistent with air contamination. However, the other two modules involved in the study were found to have a degradation in kinetics that was manifested in an 'effective' capacity loss. This kinetic degradation was found primarily in the tetrahydride absorption rate. Following further cycling, a tetrahydride capacity decrease was measured in one of the modules. This trend could be explained by ongoing interference with the catalytic mechanism of the titanium, or by a steady depletion of available aluminum wherein the initial effect would be slower kinetics followed by a capacity limitation.

Material studies were performed to try to pinpoint the cause of the performance degradation. Treatment with $\mathrm{CO}_{2}$, known to react with oxidized alanates to form carbonates, indicated significant reaction near the hydrogen inlet of the module tested. Powder X-ray diffractometry studies of samples near the hydrogen inlet showed significant crystallographic and/or morphological differences as compared to samples further from the inlet. In addition, thermogravimetric studies showed evidence of contamination only near the inlet of the module tube, although at a much lower level than would be expected from the cycling results.

Overall, the evidence suggests that contamination of the sodium alanate vessels was likely, but limited to a short section near the gas inlet. The evidence does not explain, however, why accelerated degradation in effective capacity continued following the contamination event. Nor does the evidence suggest a clear explanation of the differences found between modules.

These results demonstrate the opportunity for continued research in contamination reaction processes in metal hydride beds to allow for mitigation of capacity degradation events during the lifecycle of storage systems. 



\section{REFERENCES}

1. T. A. Johnson and M. P. Kanouff, Parameter Study of a Vehicle-scale Hydrogen Storage System, SAND2010-2140, Sandia National Laboratories, Livermore, CA, April 2010.

2. T. A. Johnson, S. W. Jorgensen, and D. E. Dedrick, A Vehicle-Scale Sodium Alanate Hydrogen Storage Demonstration System, (in preparation for publication)

3. D. E. Dedrick et al., Thermal properties characterization of sodium alanates, Journal of Alloys and Compounds, Vol. 389, pp. 299-305, 2005

4. A. Rodriguez-Sanchez et al., Expanded graphite as heat transfer matrix in metal hydride beds, International Journal of Hydrogen Energy, Vol. 28, pp. 515-527, 2003

5. D.E. Dedrick et al., Heat and mass transport in metal hydride based hydrogen storage systems, Proceedings of the 2009 ASME Summer Heat Transfer Conference, July 19-23, 2009, San Francisco, California USA

6. Dedrick, D.E. et al; "The reactivity of sodium alanates with $\mathrm{O}_{2}, \mathrm{H}_{2} \mathrm{O}$, and $\mathrm{CO}_{2}$ ", SAND2007-4960, Sandia National Laboratories, 2007

7. Behrens, R., Jr., New simultaneous thermogravimetry and modulated molecular beam mass spectrometry apparatus for quantitative thermal decomposition studies. Review of Scientific Instruments 1987, 58 (3), 451-461

8. Behrens, R., Jr., Determination of the Rates of Formation of Gaseous Products from the Pyrolysis of Octahydro-1,3,5,7-tetranitro-1,3,5,7-tetrazocine (HMX) by Simultaneous Thermogravimetric Modulated Beam Mass Spectrometry. International Journal of Chemical Kinetics 1990, 22, 159-173. 


\section{DISTRIBUTION}

4 Scott Jorgensen

Chemical Sciences and Material Systems Lab

General Motors R\&D, Planning and Fuel Cell Activities

Mail Code: 480-106-160

30500 Mound Road

Warren, MI. 48090-9055

$4 \quad$ Monterey Gardiner (DOE/EERE)

Forrestal Building

U.S. Department of Energy

1000 Independence Ave., S.W.

Washington, DC 20585

$\begin{array}{llll}1 & \text { MS9001 } & \text { Chris Moen } & 8005 \text { (electronic) } \\ 1 & \text { MS9153 } & \text { Mike Hardwick } & 8220 \text { (electronic) } \\ 1 & \text { MS9035 } & \text { Paul Spence } & 8224 \text { (electronic) } \\ 1 & \text { MS9052 } & \text { Richard Behrens } & 8128 \text { (electronic) } \\ 1 & \text { MS9052 } & \text { Jay Keller } & 8367 \text { (electronic) } \\ 1 & \text { MS9054 } & \text { Bob Carling } & 8300 \text { (electronic) } \\ 1 & \text { MS9054 } & \text { Art Pontau } & 8360 \text { (electronic) } \\ 1 & \text { MS9403 } & \text { Joe Cordaro } & 8223 \text { (electronic) } \\ 1 & \text { MS9409 } & \text { Daniel Dedrick } & 8365 \text { (electronic) } \\ 1 & \text { MS9409 } & \text { Neal Fornaciari } & 8365 \text { (electronic) } \\ & & & \\ 2 & & & 8944 \\ 2 & \text { MS9018 } & \text { Central Technical Files } & \end{array}$




\section{(1) Sandia National Laboratories}

